\title{
EL REGALISMO EN EL SEMANARIO ERUDITO DE VALLADARES*
}

Ramón BALDAQUI

Universidad de Alicante

* Este trabajo forma parte de la Memoria de Licenciatura que, bajo la dirección de Antonio Mestre Sanchis, fue defendida en la Facultad de Filosofía y Letras de la Universidad de Alicante en junio de 1983 con el título "Jansenismo y regalismo en el Semanario Erudito de Valladares». 
. 
A lo largo de las páginas que siguen vamos a ocuparnos de la ideología regalista tal como aparece en el Semanario Erudito de Valladares. Se trata de un tema, el de las manifestaciones del pensamiento religioso y político-religioso en la prensa del siglo XVIII, casi totalmente inédito, y que tan sólo ha sido abordado hasta el presente con muchas limitaciones(1).

El Semanario Erudito que publicaba don Antonio Valladares de Sotomayor, apareció en Madrid, desde el 30 de abril de 1787 hasta 1791. Salía los lunes, y cada entrega constaba de una media de seis pliegos (48 páginas), que se vendían a 4 reales al público, y a 3 a los subscriptores. Hasta la suspensión del periódico, causada por el decreto de Floridablanca de 24 de febrero de 1791, aparecieron 34 tomos en tamaño cuarto, con una extensión media de 284 páginas cada uno(2). El periódico se anunció mediante un Prospecto en el que Valladares mostraba su intención de reivindicar a los literatos, los sabios y los autores políticos del Siglo de Oro y de principios del siglo XVIII, al tiempo que achacaba al clero regular el haber sido la causa de la decadencia de las letras españolasi3).

Todos los autores que se han ocupado del Semanario han señalado su carácter regalista, sin precisar más(4). Nuestro propósito en el presente estudio será el de profundizar en los textos regalistas publicados en la revista, a fin de indicar, por una parte, el alcance y el sentido que toma el regalismo en el Semanario, y por otra, el significado que adquieren estas obras regalistas consideradas en sí mismas.

A lo largo de los 34 tomos del Semanario hemos encontrado 33 artículos relacionados con el regalismo, si bien en diverso grado, pues mientras algunos de ellos tratan exclusivamente sobre los problemas causados por las relaciones Iglesia-Estado, otros son escritos de tipo económico o politico que proponen medidas de carácter regalista. A su vez, y dentro de esos 33 artículos, cabe que hagamos una distinción cronológica, según se trate de textos de los siglos XVI y XVII (13 en total) o del siglo XVIII (20 obras); y una doctrinal, según se trate de textos regalistas de tipo jurisdiccional ( 28 escritos) o de tipo episcopalista ( 5 obras)(5). Pues en efecto, dentro de las doctrinas regalistas se pueden distinguir claramente estas dos corrientes, y no sólo en el regalismo del siglo XVIII, sino también en el anterior, como veremos. Llamaremos regalismo jurisdiccional al que 
tiene por objeto el reforzamiento del poder real mediante la atribución al monarca del mayor número de competencias en materias eclesiásticas; y regalismo episcopalista a aquél que pretende dar peso a la institución divina del episcopado frente al papado, a fin de realizar la reforma disciplinar de la Iglesia. Ambas tendencias persiguen un objetivo similar, la independencia disciplinar de la Iglesia española frente a Roma, pero sus fines son muy distintos, pues si el regalismo jurisdiccional pretende el control político y económico de la Iglesia nacional y de los eclesiásticos, el episcopalismo tiene por objeto realizar la reforma disciplinar que el centralismo y los abusos de los curiales romanos impiden y manifiesta su desconfianza hacia el poder real tanto como hacia el pontificio aunque, precisa apoyo del primero frente al segundo6).

Dentro de todo este grupo de textos hay que indicar la diferente calidad que se observa entre los textos de los siglos XVI y XVII y los del siglo XVIII. Entre las obras de los siglos XVI y XVII aparecen con frecuencia documentos de carácter oficial causados por los reyes, como Fernando el Católico y Felipe II, quen no tienen equivalente entre los del siglo XVIII. Sí aparecen, sin embargo, en ambos períodos, documentos causados por ministros y altos cargos: documentos del Conde-Duque, del virrey Fernández de Velasco, o del fiscal Fernández de Retes, en los siglos XVI y XVII, y documentos de Macanaz, Ensenada, Riol o Gándara en el XVIII. Otro género de documento oficial que aparece son las consultas que se hacen desde el poder a personajes privados que gozan de consideracion, como a Fray Hortensio Félix Paravicino en el siglo XVII, y a Mayans en el XVIII. Finalmente, tenemos también documentos no oficiales, memoriales o arbitrios dirigidos a la administración o incluso entre particulares (caso de la respuesta del Dr. Sales a D. Ximeno, del siglo XVIII). También es similar la proporción entre los textos de una y otra época que aparecen directamente dedicados a los temas del patronato real y derechos de regalías: seis sobre trece en los escritos de los siglos XVI y XVII; diez sobre veinte en los del XVIII.

Pero las discrepancias surgen cuando consideramos la distribución por temas, pues si en el siglo XVIII hallamos cuatro textos episcopalistas sobre veinte, en los siglos XVI y XVII tan sólo hallamos uno sobre trece. $Y$ la diferencia se hace mucho más importante si consideramos la entidad de las obras, pues el episcopalismo dieciochesco se halla representado por 
obras largas y de peso, mientras que la única obra de esta tendencia que aparece en los siglos XVI y XVII es el breve Parecer de D. Garcerán Albanel, que si bien no carece de enjundia, está mucho menos elaborado que sus equivalentes del XVIII. Se trata de la misma diferencia que hallamos a nivel general entre la totalidad de las obras consideradas de uno y otro período. Los textos de los siglos XVI y XVII que publica el Semanario Erudito son en general, más breves y menos elaborados que los del sigio XVIII, salvo los casos de los memoriales de Betancurt y Fernández de Retes. Los textos que se publican del siglo XVIII, por contra, suelen ser más largos y elaborados y las formulaciones que presentan del pensamiento regalista son más complejas y acabadas y en general, de un carácter que podríamos considerar más "teórico", pues tratan de fundamentar derechos o posiciones en relación con las regalías, aspecto que aparece mucho menos en las obras de los dos siglos anteriores. Cuantitativamente, el regalismo de los siglos XVI y XVII ocupa 393 páginas de la revista, frente a 1.705 del regalismo del siglo XVIII. De éstas, 666 se ocupan en desarrollar teorias episcopalistas, mientras que estas doctrinas sólo ocupan 13 páginas de las dedicadas al regalismo de los siglos XVI-XVII.

Tras hacer estas puntualizaciones, vamos a ocuparnos de los textos regalistas publicados en el Semanario Erudito a fin de considerar, en primer lugar, el alcance y el peso que toma esta corriente en el conjunto de la revista.

\section{1) PARTICIPACION DEL REGALISMO EN EL SEMANARIO ERUDITO.}

Comencemos señalando que en las 20 obras del siglo XVIII publicadas, se encuentran representadas todas las polémicas regalistas de la primera mitad del siglo, hasta el Concordato de 1753. En efecto, las polémicas ocasionadas con motivo de la ruptura con Roma de 1709 están presentes con el Dictamen del obispo Francisco de Solís, y las obras de Macanaz, sobre todo la Explicación jurídica e histórica..., el Discurso sobre el poder que algunos doctores han querido atribuir al Papa en lo temporal, y la Disertación histórica..., contra Alberoni, que dan una cumplida visión de su ideologia regalista, hasta ofrecer incluso en la Disertación histórica el 
articulado del acuerdo de París de 1714 entre el nuncio Pompeo Aldrovandi y D. José Rodrigo Villalpando, que Macanaz considera inspirado por él y como el mayor logro de su politica regalista(7). Las polémicas posteriores, ya conscientemente encauzadas a la consecución del patronato universal, aparecen representadas por los trabajos de D. Santiago Agustín Riol, el primero de los cuales, realizado por encargo real en 1726(8), aparece en el año en que se plantea por vez primera la búsqueda del patronato universal, y en que el gobierno comienza las investigaciones documentales sobre el patronato(9). De ahí que sea significativa la obra de don Santiago Riol, pues se trata nada menos que de un encargo real para que dé razón de las reformas que llevaron a cabo los Reyes Católicos en la disciplina eclesiástica y restauración de sus derechos, y para que informe del estado de los diversos archivos oficiales(10). En otras palabras, se trata de un paso previo, de establecer una base para lanzarse a la conquista del patronato, según el modelo de los Reyes Católicos, y por la vía exhumadora, desenterrando derechos perdidos (11). De ahi también que Valladares ponga el otro documento de Riol, la Representación sobre el patronato real, en conexión con los esfuerzos de la Junta del Real Patronato de 1735, hasta el punto de que piense que "dió motivo" a tales "novedades", pues aunque tal documento no puede datarse en 1735, ya que desde 1732, Riol, convicto de estafa, fue destituido, procesado y arrestado(12), y sospechamos que sea muy anterior, de 1708(13), Valladares advierte que los trabajos de Riol guardan relación con la actividad exhumadora de documentos patronales que quedó consagrada precisamente en la Junta del Real Patronato, como el camino a seguir para lograr el patronato universal. Y en efecto, vemos que los trabajos de Riol están en el origen de este camino hacia el patronato a través de la investigación de archivos.

Entre los esfuerzos regalistas de 1709 y las polémicas que comienzan en 1726 y se encauzan en 1735, está la conmoción producida por el intento reformista de 1723 mediante la bula Apostolici Ministerii, que no gusto a los eclesiásticos apegados a sus privilegios y exenciones de la jurisdicción ordinaria, sobre todo a los de las órdenes regulares y a los cabildos, pues la bula daba a los obispos cierta autoridad sobre unos y otros. Un eco tardio de las polémicas que despertó dicha bula lo encontramos en el $\mathrm{Me-}$ morial que en 1736 firmó Fray Joseph Haro de San Clemente para pedir al 
rey su aplicación en los aspectos que tocaban a la reforma de los religiosós, limitando su número según los recursos de las órdenes y sujetando la reforma disciplinar a los obispos, todo según el modelo de los reformadores de las órdenes en el siglo XVI y según las normas del Concilio de Trento(14).

Las polémicas patronales originadas tras el Concordato de 1737 aparecen representadas por la correspondencia cruzada entre Mayáns y el fiscal de la Cámara, Blas Jover, con motivo de las obras que Jover publicó en dicha polémica, contra el Concordato de 1737, y contra los diversos escritos que el nuncio publicó en defensa de los derechos de la Curia Romana; obras que fueron escritas por Mayáns a instancia de Jover, con la pretensión no sólo de contestar a dichos escritos, sino de fundar el patronato universal en la costumbre inmemorial y en un progreso histórico que demostrase la posesión y el uso de tales derechos desde el principio de la monarquía hispánica hasta su siglo(15).

Finalmente, aparece en el tomo XXV del Semanario el texto del Concordato de 1753 y en ese tomo y en el siguiente las Observaciones al Concordato de 1753, obra de Mayáns, escrita por encargo del marqués de la Ensenada, quien deseaba tener con esta obra una orientación para encauzar adecuadamente la jurisprudencia de los nuevos derechos obtenidos mediante el Concordato. Mayáns hará más, y en esta obra sugerirá el modo de utilizar estos derechos en la reforma de las deficiencias que sufre la Iglesia española, y la fundamentación del patronato universal del rey, junto con el objetivo buscado por Ensenada. Pero lo que ahora interesa es que tenemos aquí un ejemplo de jurisprudencia concordataria. Otro ejemplo de jurisprudencia sobre el Concordato de 1753 lo ofrece Gándara en su Informe, que funda el absoluto y único derecho real sobre el patronato. Ahora bien, a partir de aquí ya no aparecen más textos alusivos a los problemas regalistas. Las polémicas posteriores al Concordato de 1753 no aparecen en el Semanario. Se evita toda referencia a las tensiones recientes de tipo regalista, lo que creemos se debe al deseo de ocultar las tensiones politicas internas o externas y de mantener el secreto sobre las materias de Estado. El Semanario se limita, pues, al camino recorrido hasta alcanzar el patronato universal, y a su uso, pero aqui se detiene. $Y$ aunque aparece algún texto posterior a 1753-como la Pregunta de Don Ximeno y 
la Respuesta del Doctor Don Agustín Sales-se trata de obras de carácter reformista que aluden a problemas económicos y que no hacen referencia a cuestiones de patronato.

En cuanto a los textos de los siglos XVI y XVII, se trata de obras diversas que no forman grupos centrados en ninguna polémica o problema concreto debatido en esta época. Abundan los documentos de tipo más o menos oficial, emitidos por las autoridades o a petición suya, como la Carta de Fernando el Católico, la Instrucción al presidente Covarrubias, y la Instrucción al Consejo de Cámara ambas de Felipe II, el Gran Memorial del Conde-Duque de Olivares, la Carta del virrey Fernández de Velasco o la Proposición de Paravicino; y de los dos documentos de más extensión que aparecen sobre el tema regalista, tan sólo uno tiene por fin la defensa y aumento de la jurisdicción real (la Conveniencia y concordia de ambas jurisdicciones en materia de inmunidad local, de Retes) mientras el memorial de Betancurt más bien busca fundar una limitación del derecho patronal en Indias_la obligación de proveer capitulares y naturales-si bien su objetivo es procurar el bien de la Iglesia indiana(16). Finalmente, señalemos que en uno y en otro siglo aparecen textos de carácter político o económico que se ocupan de diversos problemas planteados por el estado eclesiástico, sobre todo problemas de tipo económico o demográfico, sin que falten referencias a problemas de disciplina o jurisdicción eclesiástica, pero que no permiten que se les encuadre en ninguna de las polémicas regalistas.

En cuanto a la distribución de las obras regalistas dentro de la revista, observamos que los escritos de esta clase aparecen a lo largo de toda la vida de la revista, desde el tomo I al XXXIV, pero su distribución no es uniforme. $Y$ asi, en primer lugar, debemos indicar que las obras regalistas de los siglos XVI y XVII aparecen con una frecuencia creciente conforme avanza la vida de la publicación, sin que observen una distribución lineal, sino que se concentran en pequeños grupos, entre los cuales hay periodos en que no aparece ninguna obra de esta clase. Tras las publicadas en los tomos I y II, no vuelve a aparecer ninguna otra hasta el tomo $X I$, en que se publican dos obras (el Gran Memorial de Olivares y el Unico desengaño, de Somoza), y el XIV, que publica el Parecer de D. Garcerán Albanel. Luego hay que esperar a los tomos XIX y XXI-XXII para volver a encontrar obras regalistas de los siglos XVI y XVII, que ya no vuelven a aparecer hasta lostomos XXVIII- 
$X X I X-X X X$, en que se publican cuatro obras, y finalmente, otra en el tomo XXXIV. El mayor número de textos aparece, pues, en los años 1789-1790 y en el único tomo de 1791. Pero las obras de mayor extensión-las de Retes y Betancurt-aparecen en los tomos XXI y XXII. Digamos finalmente que las obras puramente regalistas y las obras de carácter preferentemente económico o político que sugieren medidas regalistas, observan una similar distribución, tanto en este caso como en los demás grupos.

Respecto de las obras del siglo XVIII, comenzando por las de tendencia episcopalista, observamos que aparecen en los años 1788-1790. Su publicacion abarca el periodo central de la vida del Semanario, entre los tomos IX y XXVI, sin que aparezcan textos de este carácter en los ocho primeros ni en los ocho últimos tomos de la revista. Las obras episcopalistas tampoco se distribuyen uniformemente, sino en tres grupos que aparecen at principio, en medio y al final del periodo (tomos IX, XV y XVII, XXV y $X X V I)$. Si consideramos la ideología episcopalista en su conjunto, los textos que la representan, incluyendo también la obra de Albanel del siglo $X \mathrm{VII}$, siguen observando la misma distribución, con la mayor concentración en los tomos XIV-XV-XVII (obras de Albanel, Haro y correspondencia Mayáns-Jover), a caballo entre los años 1788 (XIV-XV) y 1789 (XVII). En conjunto, los textos episcopalistas aparecen desde mediados de 1788 (Solís) a principios de 1790 (Observaciones de Mayáns). Sin embargo, por la extensión de los textos, el período más importante es el último, debido a la obra de Mayáns, quien es también el autor regalista y episcopalista mejor representado en el Semanario, aunque Valladares no parece percibir el episcopalismo mayansiano.

Finalmente, las obras regalistas de carácter jurisdiccional del siglo XVIII aparecen concentradas en los tomos III a XVIII durante los años de 1787 a principios de 1789, sin que aparezcan luego obras de este carácter a lo largo de la vida de la revista, ni siquiera como observaciones en obras de otro carácter, de tipo económico o político. Precisamente esta concentración es la causa de que se observe una mayor abundancia de obras regalistas en el primer periodo de la vida del Semanario, entre los tomos I a XIX, en los que aparecen veinticinco de las obras que venimos considerando, mientras que tan sólo aparecen ocho títulos en los tomos comprendidos desde el XXI al XXXIV. 
Observamos, por tanto, que el regalismo beneficial del siglo XVIII se concentra al principio de la revista, en un período de poco más de año y medio, de los más de tres años y medio que duró el Semanario, y que veinticinco de las treinta y tres obras publicadas aparecen en los primeros dos años de nuestra publicación, hasta el tomo XIX. ¿Quiere esto decir que el Semanario Erudito abandona su orientación regalista, o al menos la atenúa, a partir del tomo XIX?. Esta afirmación, que a primera vista pudiera parecer correcta, debemos tomarla con reservas. En primer lugar, es precisamente en este segundo período cuando aparecen la mayoria de las obras regalistas anteriores al siglo XVIII, y además las de mayor entidad, cuales son las de Retes y Betancurt en los tomos XXI y XXII, y otras tan significativas como la Instrucción al Consejo de Cámara de Felipe II. Y en segundo lugar, es en este período en el que aparece la obra regalista más importante por su extensión y significado, de todas las publicadas en el Semanario, que son las Observaciones al Concordato de 1753, de Gregorio Mayáns.

Por otra parte, debemos indicar que parece darse un cambio de orientación en el regalismo de la revista: ésta apuntaria ahora hacia el reformismo eclesiástico y el episcopalismo a partir señaladamente del tomo XIV, en que se publica el Parecer de Albanel, y continuaria con las obras de Haro de San Clemente (tomo XV), la Respuesta de Agustín Sales (tomo XVI), que presenta un carácter reformista en la línea mayansiana(17), Mayáns (tomo XVII), Betancurt (tomo XXII, limitación del regalismo por la búsqueda del bien de la Iglesia), Mayáns de nuevo (tomos XXV y XXVI) y quizá la Instrucción al Consejo de Cámara en algunos aspectos (tomo XXX)(18). Indiquemos en este sentido que a partir del tomo XXVI aparecen el mayor número de obras publicadas en el Semanario que presentan tendencias jansenizantes (dejando aparte las de Mayáns); pero esta corriente se presenta en nuestra revista débil y difusa, y con un marcado carácter regalista(19).

Cabe indicar que el cambio de tendencia en el regalismo de la revista se da en el año 1789, coincidiendo con el acceso de los "jansenistas» a puestos clave de la vida nacional en el gobierno, la enseñanza o la Iglesia. Precisamente, la edición de las Observaciones de Mayáns, que Roda no se atrevió a publicar, y que aparecen en nuestro Semanario, es el hito que Mestre coloca para señalar este nuevo dominio ideológico(20). Sin em- 
bargo, las obras propiamente episcopalistas son tan escasas, aunque de peso, y su aparición tan temprana con respecto al acceso de los «jansenistas" al poder (pues a principios de 1790 , tras las Observaciones mayansianas ya citadas, dejan de aparecer), que no nos atrevemos a afirmar que el Semanario sufra un cambio radical de orientación, y menos a que éste venga impuesto desde el poder, a pesar de que el gobierno facilitara la edición de dichas Observaciones, como lo demuestra el hecho de que el texto publicado en el Semanario Erudito sigue el original mayansiano que fue enviado al marqués de la Ensenada y que se conservaba en los archivos de la Secretaria de Estado(21). Y a pesar de que es innegable una acentuación del interés de la revista por los temas reformistas a partir de estas fechas, no creemos que esta razón pueda explicar el que el Semanario cada vez publique menos obras regalistas, sobre todo obras de tipo jurisdiccional y del siglo XVIII. Asi pues, podemos indicar que el comienzo de las publicaciones regalistas en el Semanario coincide con el empujón regalista que supone la creación de la Junta de Estado y la instrucción que le da Floridablanca(2); sin embargo, no hemos podido hallar un fenómeno que pueda explicar suficientemente la atenuación brusca que puede observarse, aunque con las reservas ya expresadas, en el ritmo de publicaciones regalistas que sigue nuestro periódico.

Finalmente, vamos a tratar de establecer el peso del regalismo dentro de la revista, en primer lugar, por razón del número de textos en relación con el total, y en segundo lugar, por el número de páginas que ocupa. Para establecer el porcentaje de artículos regalistas en el Semanario Erudito nos guiaremos por las entradas de los índices. Estos no están confeccionados de un modo totalmente fiable, pues mientras una obra como el Informe de Riol tiene en el índice cuatro entradas-una para el Informe, otra para la carta que Riol envió con él, y otras dos para la orden del rey pidiéndole que informara de personas competentes para la inspección de archivos y la respuesta de Riol confesándose incapaz de ello(23) _en cambio, en el tomo XVII, la correspondencia entre Mayáns y el conde de Aranda, la correspondencia Mayáns-Jover, la correspondencia entre Mayáns y Macanaz y la censura mayansiana a la España primitiva de F. X. M. Huerta y Vega, aparecen reunidos bajo el título Cartas eruditas y criticas de Don Gregorio Mayáns y Siscar, á varios asuntos; con la nota del Editor (quien 
pone en realidad tres notas), único que figura en el indice. Sin embargo, nos guiaremos de las entradas del indice de la revista porque pretendemos ajustarnos lo más posible al punto de vista del editor, y porque, de modo aproximado, ofrecen una visión cuantitativa bastante aceptable.

Asi pues, sobre un total de 229 entradas en los índices, excluidas las notas del editor y las listas de suscriptores, es decir, sobre 229 entradas de artículos, un total de 39 corresponden a las obras que venimos considerando, que son las que plantean, de un modo u otro, problemas regalistas. Es decir, el $17 \%$ de los artículos de la revista se ocupan de temas regalistas.

Ahora bien, para tener una idea más precisa del auténtico peso del regalismo en el Semanario Erudito, debemos medir el número de páginas que ocupan estos temas. Los 33 artículos que hemos considerado como el "corpus" regalista del periódico, y a los que correspondian esas 39 entradas en los indices, totalizan 2.098 páginas de texto(24), que sobre el total de 9.673 páginas que comprenden los 34 tomos del Semanario (excluidas las listas de suscriptores), representan un porcentaje del $21^{\prime} 6 \%$. Es decir, más de la quinta parte del Semanario Erudito está dedicada a textos que presentan tendencias regalistas.

Las 2.098 páginas de textos regalistas se desglosan del siguiente.modo: 1.419 páginas corresponden al regalismo que hemos Ilamado jurisdiccional y 679 al regalismo episcopalista, o sea, respectivamente el 67 ‘ $6 \%$ y el $32 ، 3 \%$. Es decir, que a pesar de que tan sólo cinco artículos son episcopalistas sobre el total de 33 , estos cinco textos tienen un peso mucho mayor por su extensión de lo que este número da a entender, y ocupan un tercio del total del espacio dedicado al regalismo. Tenemos pues un núcleo de textos episcopalistas muy apreciable tanto por su calidad como por su peso sobre el total de lo publicado en materias regalistas. $Y$ este peso es aún mayor de lo que parece a primera vista, como podremos comprobar.

De las 1.419 páginas dedicadas al regalismo jurisdiccional, 380 corresponden a los textos de los siglos XVI y XVII. En ellas, los textos puramente regalistas, que podriamos Ilamar "doctrinales", ocupan 222 páginas, mientras que de las 158 restantes, 110 son de textos políticos que abordan desde un punto de vista regalista los problemas que causa en la sociedad civil el estado eclesiástico, ya económicos, ya sociales o políticos; o bien los problemas de las relaciones con Roma, mientras que las 48 páginas 
restantes son de textos económicos que abordan los problemas que causan las propiedades o los privilegios económicos del clero. Los textos de tendencia jurisdiccional del XVIII ocupan 1.039 páginas, de las que 406 pertenecen a textos «doctrinales», 572 a textos políticos que abordan los problemas ya enunçiados, y 61 a textos económicos. Es decir, que en total 528 páginas de texto corresponden a los escritos puramente regalistas, mientras que las 791 restantes, hasta 1.419 , corresponden a textos políticos o económicos que tocan algunos de los problemas causados por las relaciones Iglesia-Estado; en sentido regalista. Ahora podemos apreciar el verdadero peso de los textos episcopalistas, que ocupan 679 páginas enteramente "doctrinales", frente a las 628 del regalismo jurisdiccional.

¿Invalidan, pues, estas cifras, nuestra anterior afirmación de que el Semanario no sufre un cambio radical de orientación hacia el episcopalismo?. No lo creemos. Recordemos en primer lugar que hemos establecido que la revista sufre una progresiva evolución favorable al episcopalismo. Sin embargo, pensamos que, a pesar de la entidad de las obras publicadas y de su extensión, el número de títulos es demasiado escaso como para que pueda hablarse de que la revista toma una decidida orientación y un acento predominantemente episcopalista. $Y$ por otra parte, estos títulos se publican en un periodo no demasiado largo, justo a la mitad de la trayectoria de la revista, y demasiado dispersos, para que pueda hablarse de que la revista se vuelve exclusiva o fundamentalmente episcopalista. Por último, aunque cesan de publicarse textos jurisdiccionales del XVIII, continúan publicándose obras regalistas jurisdiccionales de los siglos XVI y XVII, por lo que el factor jurisdiccional no desaparece del todo.

Por otro lado, no cabe despreciar estos textos políticos o económicos fundamentalmente, que enfocan desde una perspectiva regalista algunos de los problemas planteados por las relaciones Iglesia-Estado, y que totalizan nada menos que 791 páginas de textos (no enteramente dedicadas al regalismo, claro está). Son un testimonio de ese "regalismo general" de que Sarrailh habla en la segunda mitad del siglo XVII (25), del "regalismo ambienten, el más decisivo de todos, que Teofanes Egido atestigua que opera a lo largo de la centuria ilustrada(26) y que este autor considera necesario tener presente para conocer el verdadero alcance de las formulacio- 
nes doctrinales y políticas regalistas. Estos textos, por tanto, si no son tan decisivos como los que abordan puramente problemas regalistas, son sin embargo indispensables para dibujar un panorama lo más correcto posible del regalismo de los siglos XVI al XVIII y por tanto, de su proyección en el Semanario Erudito.

Todas estas obras podemos decir que se publican con plena conciencia de su significado regalista por parte de su editor, don Antonio Valladares, como lo dan a entender las Notas del editor que antepone a algunas obras. Citaremos tan sólo algunos ejemplos.

Al comienzo del tomo VII del Semanario, que es el primero de una serie de tomos dedicados en su mayor parte a las obras de Macanaz, Valladares inserta una Nota del Editor(27), en que ofrece noticias sobre la vida del famoso Fiscal de Felipe $V$, y un catálogo de sus obras, especificando Valladares las que conoce, las que tiene y las que piensa publicar. La biografía de Macanaz se encuentra narrada de modo muy sucinto, ya que "hay un cierto género de verdades, que aunque no sea culpa conocerlas, puede ser delito manifestarlasw(27 bis) sin embargo, tales precauciones no impiden que nuestro editor prodigue elogios sin tasa al grande hombre y su celo al servicio del rey:

Lo mucho que trabajó en beneficio de la Corona, de sus Regalías y de la Patria, parece increible; pero su zelo, infatigables tareas y ánimo recto é incorruptible, le produxeron muchos enemigos(28).

Pero a pesar de sus enemigos, y siempre según Valladares, Macanaz "Siempre hablo con aquella libertad Christiana, que debiendo ser de todos celebrada, suele ser de pocos aplaudida". Por lo demás, todas sus desgracias, nacieron de defender "las Regalias del real Patronato, las leyes y las glorias de la nación «(29). Y la misma admiración que el hombre despiertan en Valladares sus obras:

Nadie nos quitará la gloria de ser los primeros que logramos publicar algunas obras de este autor. Ojalá tuvieramos todas las que compuso, para dar con ellas un eterno nombre á nuestro periódico, y una exquisita instruccion á nuestros lectores(30). 
Así pues, no cabe la menor duda sobre la admiración que D. Antonio Valladares sentía por la obra y los escritos regalistas de D. Melchor de Macanaz. Pero también percibia claramente el alcance de cada una de las obras que publicaba; y así, del Discurso sobre el poder que algunos doctores han querido atribuir al Papa en lo temporal, original del mismo Macanaz, afirma en la Nota del editor(31) que lo precede:

Puede mirarse este discurso, como un epilogo de lo mas que se refirió á la Junta del Clero de Francia, para proceder á la primera de las quatro proposiciones ó articulos que contiene sú declaracion de 19 de Marzo de 1682, sobre potestad Eclesiastica. Saben todos la fermentación que ocasionó entre los Teólogos esta declaracion, y lo mucho que entonces se escribio en el asunto, y la defensa por el Clero de Francia, y sus quatro proposiciones, que todo se publicó después de muerto el célebre Obispo de Meaux el S. Bosuet, que habia tenido la mayor parte en aquella declaracion(32).

Como vemos, el galicanismo de la obra, cuyo fin es destruir los fundamentos de la doctrina de la potestad indirecta de los Sumos Pontifices sobre lo temporal, y que afirma rotundamente la falibilidad papal(33), era bien conocido por Valladares, quien afirma del discurso que sus expresiones "en muchas partes son bastante arrogantes" (34).

Otro ejemplo lo encontramos en la Nota del editor(35) que figura al frente de las Observaciones al Concordato de 1753, de Mayans, de quien dice Valladares:

$Y$ es muy digno de celebrarse el fin que se propuso de hacer una sólida demostración de los derechos de la Corona al Patronata universal, y otras regalias, y de las graves ventajas que logra España con el ajustamiento del presente Concordato, por no haber tenido en uso y práctica constante los derechos y regalías que le corresponden, ni los medios seguros y convenientes que deben tomarse, para que con su execucion se consigan todos aquellos altos fines á que se debe aspirar para el bien y felicidad comun de esta monarquía(36).

Entre la preciosa variedad de puntos á que se extiende nuestro Autor, hay muchos muy útiles y aun esenciales para la mejor direccion y acierto en el uso y práctica del Concordato(37). 
Podemos concluir, por tanto, que Valladares veía perfectamente el carácter radical, e incluso abiertamente galicano, de los artículos regalistas de su revista, y por tanto no cabe dudar de la línea ideologica que pretendia imprimirle. $Y$ aunque en muchas ocasiones, nuestro editor no pone notas al frente de los textos que publica, los títulos no dejan dudas en muchas ocasiones sobre el contenido de las obras, como por ejemplo el Dictamen del obispo Solís, "sobre los abusos de la Corte Romana, por lo tocante a las Regalías de S. M. Católica, y jurisdicción que reside en los Obispos", o bien sobre su significado, como la Representación sobre el patronato real, de Riol, "que dio motivo a las novedades del año 1735".

Añadamos que nuestro editor contaba con el favor, e incluso con el apoyo de las esferas del poder para su plan de publicaciones regalistas, manifestado en que se le permite publicar todos estos textos regalistas, aunque a veces debiera poner advertencias a los mismos por orden del Consejo de Castilla(37 bis); manifestado también en el agrado con que Carlos III leía la revista, según testimonio de su confesor; en la plácida vida de nuestra publicación hasta el decreto de Floridablanca, y en la licencia que al cabo de año y medio de suspensión se le concedió fácilmente por Carlos IV, para continuar la aparición del periodico(38). Y finalmente, en que desde la Secretaria de Estado se le facilitó el texto de las Observaciones al Concordato de 1753 de Mayáns, y se le autorizó a publicarlas (39), lo mismo que se le autorizó (y quizá también se le facilitaran de los archivos oficiales) la publicación de textos como el Informe reservado de Gándara, o la Explicación jurídica e histórica de la consulta que hizo el real Consejo de Castilla al rey nuestro señor, de Macanaz, textos de caracter comprometido para organismos oficiales o personajes sobresalientes, y que por ser "materia de Estado", precisarian de la aprobación de la Secretaría de Estado para ser publicados $(40)$. Y aunque el único tropiezo con la censura gubernamental que tuvo el periódico fue por causa de uno de estos escritos, precisamente la Explicación jurídica e histórica de Macanaz ${ }^{41)}$, debemos señalar que esta obra se expresa muy duramente ( $y$ en tono bastante insolente) sobre el Consejo de Castilla, violando así lo dispuesto en la Real Orden de 29 de noviembre de 1785, que disponia que los periódicos no debian servir para ridiculizar a los cuerpos constituidos(42), además de que la Explicación se publica en el tomo IX, antes de las 
Observaciones mayansianas. Esto demuestra, según creemos, que el regalismo del Semanario de Valladares se ajustaba a las directrices que emanaban desde el poder y contaba con la aprobación y el apoyo de esas mismas esferas del poder.

\section{2) LA DOCTRINA REGALISTA EN LOS TEXTOS DEL SEMANARIO ERUDITO.}

Habiendo ya considerado el alcance y el sentido que toma el regalismo como corriente de pensamiento político-religioso, en el conjunto del Semanario Erudito, debemos pasar a la segunda parte de nuestro estudio, al contenido ideológico y el alcance de las obras publicadas en la revista y que tienen contenido regalista, consideradas en sí mismas; de lo que nos ocupamos a continuación.

Considerando en su conjunto los textos regalistas que publica el Semanario Erudito de Valladares, hay un aspecto que resulta evidente: la continuidad entre el regalismo de los siglos XVI y XVII y el del siglo $X V \mid I(42$ bis). Esta continuidad la detectamos en tres niveles: en primer lugar, a nivel de los hombres; en segundo lugar, a nivel de autores y de modelos; y en tercer lugar, a nivel de problemas, de soluciones y de principios, es decir, a nivel de temas regalistas.

El primer nivel, el de los hombres, es el más evidente. En este grupo comprendemos a aquellas personas que habiendo nacido y adquirido su formación a finales del siglo XVII, llegan ya maduras al siglo XVIII, en el que desarrollarán su actividad regalista. Podemos señalar en primer lugar el caso de D. Luis de Salazar y Castro, del que el Semanario Erudito publica un texto atribuido, datado en $1687(43)$. Este personaje alcanzó posteriormente cargos en la administración borbónica, y murió ya muy avanzado el reinado de Felipe V: señalemos que la Explicación jurídica e histórica de la consulta que el real Consejo de Castilla hizo al rey nuestro señor, de que ya hemos hablado, le fue encargada a Macanaz ante el hecho de que Salazar y Castro, a quien originalmente se dio el encargo, enfermó y no pudo desempeñarlo(44). Otro caso es el de D. Santiago Agustín Riol, paje de bolsa del marqués de Mejorada, quien fue iniciado por éste en la búsqueda de documentos relativos al patronato sucediendo al marqués en esta tarea 
desde 1697, trabajo que continuó en el nuevo siglo, llegando a desplazarse a Simancas en 1711 y 1713(45). Su tarea llamó primero la atención de Macanaz, que protegió a D. Santiago en los inicios de su carrera(46); posteriormente también consiguió interesar al rey Felipe $V$ que le encargó el Informe de 1726(47), como ya hemos visto. Riol es un ejemplo perfecto de la transposición de hombres y de tendencias regalistas de un siglo a otro y de una dinastía a otra, pues su tarea, comenzada con la administración austríaca, fue luego bien acogida por los Borbones y alimentó la utendencia exhumadora" que fue la base de los esfuerzos patronales de 1726 y de la Junta del Real Patronato de 1735(48).

Pero los ejemplos más preclaros son los de Solís y Macanaz. Los dos principales escritores regalistas del reinado del primer Borbon, inmersos ambos en las disputas con Roma surgidas a partir de 1709 , son hombres que se han formado en el siglo XVII y que han adquirido en él su ideologia en sus rasgos fundamentales. Macanaz se formó a últimos del siglo XVII en el ambiente regalista de Salamanca, de donde tomó su orientación antirromana que le durará el resto de sus dias(49). Solis se nos presenta como continuador de la línea eclesiológica de los Padres españoles del Concilio de Trento(50). Ambos son, pues, muestra de los hombres que pasan de un siglo a otro su ideología regalista, doblemente significativos por ser los iniciadores en el siglo XVIII de las dos corrientes regalistas, jurisdiccional y episcopalista, respectivamente, que actuarán durante toda la centuria, y formados a fines del XVII, son en suma los iniciadores del regalismo borbónico.

El segundo nivel, la continuidad en los autores y modelos de actuación, ha sido repetidamente señalado por los diversos tratadistas del tema (51). Nosotros nos limitaremos a indicar algunos de los ejemplos más sobresalientes que pueden observarse. En primer lugar, señalaremos que en el sigło XVIII se toma como modélicas las actuaciones de algunos reyes anteriores: Mayans y Macanaz señalan el cuidadoso sistema de informaciones que Felipe II instituyó, a fin de conocer a los más dignos para el nombramiento de los obispos: a cuyo sistema atribuyen el que en su tiempo se eligiesen los mejores candidatos para estos cargos(52). Riol toma por modelo la acción de los Reyes Católicos tanto en el campo de la reforma eclesiástica como en el de la obtención de regalías de la Santa Sede, y cita 
con elogio las actuaciones de Felipe II en la investigación de las regalías y en la custodia de los documentos, evitando la pérdida y dispersión de los papeles con la fundación de Simancas y el establecimiento de ordenanzas al respecto(53). Hay que señalar la admiración que Solís y Mayáns sienten por los Padres Conciliares de Trento, y su actuación. Solís elogia al obispo de Segovia y al arzobispo de Granada, que intervinieron en el Concilio por la declaración dogmática del origen cristológico de la jurisdicción episcopak54). Mayáns tomará las palabras de Fr. Bartolomé de los Mártires en Trento como base de su opinión de que hay que elegir al más digno para la cura de almas(55). Ambos autores toman como modelo la Iglesia española del tiempo de los godos, cuya situación independiente de Roma en lo disciplinar les parece el objetivo supremo a alcanzar(56). Fr. Joseph Haro toma como modelo constante las reformas de las ódenes, y los reformadores del siglo XV(57). Y finalmente, recordaremos que Mayáns toma el recurso a la historia como la base en que probará el derecho que, por uso y cos. tumbre inmemorial, tienen los reyes de España al patronato universal(58).

Pero no se trata sólo de los modelos, sino también de los autores de otras épocas. Ya los autores del XVII citan las obras de otros autores anteriores de los siglos $X V$ y $X V I$, y asi vemos que $D$. Luis Betancurt cita, entre otros, a juristas como Covarrubias y Burgos Paz, y teólogos como Soto, Cayetano y Vitoria; mientras que Retes citaba a Covarrubias, El Tostado, Antonio Agustín y el Padre Mariana; además de otros autores contemporáneos a ellos(59). Pero es en el siglo XVII cuando se produce una mayor floración de juristas en este campo, y los autores del XVIII conocerán a unos y a otros, juristas, pero también teólogos. Tan sólo veremos algunos ejemplos. Macanaz, en primer lugar, cita como ya hemos visto, a propósito de la reforma de los regulares y la limitación de sus haciendas, a Melchor Cano, al Ilustrísimo Sosa, a D. Mateo Lisón y Biezma, autor conocido por su audacia y director de la oposición de las Cortes frente al Conde-Duque de Olivares, y finalmente, la consulta del Consejo de Castilla de 1619 y el Memorial de Chumacero y Pimentel(60). Por otra parte, Mayáns también conoce los autores del pasado, y cita al respecto, no sólo repertorios de fuentes (summas de concilios de Carranza y Aguirre), sino muchos otros autores, teólogos y juristas: de entre los primeros destacan Melchor Cano, Alava y Esquivel, el doctor Velasco, Arias Montano; y de los segundos, Pedro 
Juan Belluga, Egea Talayero, Covarrubias, Vázquez Menchaca, Antonio Agustín, Palacios Rubios, Ramos del Manzano(61), y también conocia a Salgado y Chumacero, a pesar de que no sentía simpatía por ninguno de ambos(62).

Finalmente, en un tercer nivel, tenemos la continuidad en los principios y temas regalistas. En primer lugar, el presupuesto de que parte toda ideologia regalista es el de la independencia de las jurisdicciones espiritual y temporal. Esta separación la encontramos expresamente afirmada por Quevedo en el siglo XVII, quien la encuentra sancionada por el mismo Cristo(63), y todavía en este siglo, la expresan Fr. Hortensio Félix Paravicino, José Fernández de Retes y D. Garcerán Albanel(64) En el siglo XVIII indican expresamente esta independencia Macanaz y Mayáns(65). La potestad espiritual, según esto, pertenece al papa, y la temporal al rey, y sobre lo temporal, la Iglesia no tiene ninguna autoridad, afirma Macanaz ${ }^{66)}$. Esta potestad temporal el rey la recibe de Dios, y éste es el origen de su autoridad en el campo de las cosas temporales de la Iglesia, según afirma Albanel en el siglo XVII, y en el XVIII Mayáns y Macanaz(67), pues la Iglesia está en el Estado, afirma Macanaz(68), y los eclesiásticos son súbditos en lo temporal, como expresamente lo afirman tanto D. Melchor como D. Gregorio, y también el capitán Somoza y el virrey Fernández de Velasco lo dan a entender(69). Así mismo la dignidad real es por sí fundamento de las facultades reales en el campo de las regalías, como opinan Fernando el Católico y su comentarista Quevedo, y el arzobispo Albanel y D. Luis Betancurt(70), y en el siglo XVIII, el obispo Solís y don Santiago Agustín Riol, quien también lo refiere a la política de los Reyes Católicos(71). El alcance que estos diversos autores conceden a estos derechos es diverso. La mayoría derivan de estas potestades la regalía de protección de la Iglesia española (lo que lleva a que Felipe II y Macanaz hagan de la religión cuestión de Estado)72), y de la disciplina eclesiástica (Betancurt, Mayáns, Solis, Macanaz, Haro, Ensenada, Albanel(73). Esta protección es la base de las actuaciones regalísticas de los reyes, pero tiene diverso contenido según los autores. Para Mayáns es la base de su actuación regalista, por la obligación que tiene el rey de ocuparse de sus súbditos eclesiásticos, de guardar la disciplina incluso frente a las medidas emanadas de Roma que puedan dañarla, y por su potestad sobre la inmunidad eclesiástica, que el 
rey mismo ha concedido mediante la cesión de su jurisdicción a los obispos(74). Solís y Macanaz también la colocan en la base de sus actuaciones regalistas, el primero porque hace al rey protector de sus vasallos, lo que le constituye en la obligación de proteger los derechos de los obispos frente a las usurpaciones romanas(75); Macanaz, porque como protector de la disciplina y padre de sus vasallos, tiene el rey la obligación de mantener la observancia religiosa, y de oponerse a los daños que puedan sufrir sus vasallos por las exacciones de dinero, y los abusos de jurisdicción causados por el proceder de la Curia romana o de los eclesiásticos(76). Para Albanel, el rey debe oponerse a las disposiciones romonas que perjudiquen la disciplina y dañen las facultades de los obispos(77). En cambio, para Haro, el rey debe limitarse a cuidar de que se cumplan las disposiciones papales y se eviten los escándalos(78), y para Betancurt, a procurar el bien de la Iglesia, pero dentro de las facultades estrictamente concedidas por la Santa Sede 79 .

Las regalías mayestáticas reconocen un origen diverso: en primer lugar, la soberanía real, que faculta al rey Fernando el Católico para imponer el exequatur ${ }^{80)}$ Este mismo origen es admitido por don Santiago Agustín Riol(81), pero sin embargo es combatido por Mayáns, a quien le parece que es una doctrina "detestablex(82). El origen universalmente admitido de las regalías son los derechos de fundación, edificación, dotación y conquista, títulos canónicos, expresamente citados por Betancurt, por Mayáns y por Riol y Gándara, junto con las concesiones apostólicas(83) Pero cada autor pone un acento diferente: para Betancurt, lo esencial son las concesiones apostólicas(84), mientras que para Mayáns, el derecho real descansa en los justos títulos canónicos(85). Riol en cambio, coloca en un plano de igualdad ambos origenes, y añade el de "cesión de los pueblos" como nuevo título por el que puede el rey desempeñar regalias, título que por otra parte, no aparece como tal en ningún otro autor(86).

La jurisdicción sobre las regalías compete en exclusiva al rey, única y absolutamente (Gándara)(87), y la que ejercen los ministros, consejos y tribunales es delegada, sin que puedan tener por si autoridad ninguna, como afirman Fernando el Católico y Quevedo, y fundamenta extensamente Macanaz ${ }^{88)}$. Todos los derechos de regalía competen al rey, afirma Gándara, y los que detentan otras personas e instituciones son por concesión real(89). 
El rey está facultado a resistir a quienes pretenden perjudicar su derecho y facultades, e incluso es un deber para él la defensa de la jurisdicción real por los medios más enérgicos: Fernando el Católico llega a pensar en el "rompimiento" con Roma, y toma medidas contra los ministros del papa, e impone el exequatur(90). También Retes y Albanel recomiendan el exequatur y la suplicación de las bulas que atenten contra la autoridad real y contra el buen orden en materias disciplinares(91). Macanaz afirma que las bulas que atentan contra el poder temporal de los reyes no tienen otro efecto "que ser condenadas públicamente como abusivas»(92). Gándara recomienda la retención de las letras apostólicas que perjudican el patronato, y Mayáns recomienda el exequatur y la suplicación de bulas que perjudiquen la disciplina(93). Este derecho comporta el de reintegrarse en las piezas patronales y derechos que corresponden al rey y que no ejerce por haberle sido usurpados o discutidos: para ello, Riol recomendará la investigación documental, y Mayáns la averiguación histórica de los derechos en cuya posesión estaban los antiguos reyes de España, y de que ahora carecen(94). Retes, finalmente, fundamenta el "auto de legos" en los reos convictos acogidos a sagrado como un caso puramente de justicia seglar y por tanto, de jurisdicción real(95).

La actuación regalista persigue la exaltación y la defensa de la preeminencia real: así lo afirma Fernando el Católico y Quevedo y lo indica Riol respecto-precisamente-de los Reyes Católicos(96). Pero también persigue el bien de la Iglesia: y así refiere expresamente Riol que uno de los objetivos de los Reyes Católicos al perseguir el control de los nombramientos eclesiásticos, y la independencia disciplinar de la Iglesia española era el restaurar la disciplina eclesiástica(97). El doble camino que marcan los Reyes Católicos es el que seguirán los regalistas para lograr el bien de la Iglesia: en primer lugar, mediante el nombramiento de los mejores para los cargos eclesiásticos. La necesidad de proveer los mejores es indicada por Felipe II en su Instrucción al Consejo de Cámara, y por Olivares en su Instrucción a Felipe IV(98). También recomienda esta necesidad Betancurt, quien considera que las mejores provisiones son las que se hacen en naturales y capitulares, y fundamenta extensamente la obligación del rey de proveer a los naturales y capitulares por más idóneos(99). Y en el XVIII, Macanaz recordará la obligación de proveer a los mejores ${ }^{(100)}$. Esta provisión de los mejores será una de las ventajas que Riol encuentra en el uso del 
patronato por el rey, y será una de las ventajas más importantes que Mayáns encuentre en el Concordato de 1753(101). Las provisiones de Roma son malas, y de ahi la importancia que se da al derecho real de provisión, pues la elección de los mejores lleva consigo el buen gobierno de las almas, como no dejan de indicar Riol y Mayáns, en el XVIII, y Betancurt en el XVI(102), quien señala también la necesidad de evitar las largas vacantes(103). En esto coincide con Mayans y con Macanaz y Felipe II(104): estos últimos además indican la necesidad de vigilar a los provistos para que cumplan con sus deberes pastorales(105).

Aparte del mal gobierno de las almas, otros daños que se evitan con las buenas provisiones reales es la saca de dinero, denunciada por Betancurt, por Salazar y Castro y por Albanel en el.XVI|(106), y por Mayáns, Solís y Riol en el XVII(107), y que Macanaz intentará encauzar mediante el acuerdo de 1714(108); y también se consigue el premiar a quienes lo merecen, con los beneficios eclesiásticos, como indica Betancurt, y también Riol, Mayáns y Cangas Inclán en el XVIII(109). Finalmente, si el rey provee los cargos según el sistema de informes, tal como lo instituyó Felipe II, se nombrará a los mejores y se evitará molestias y gastos a los pretendientes que acuden a la Corte: y si el nombramiento pasa al rey, se evitará a los pretendientes el acudir a Roma. Estas ventajas perseguia Felipe II al instituir el Consejo de la Cámara, y las señala también Betancurt en el XVII, y Riol y Mayans en el XVIII(110).

Otro tipo de problemas son los que plantea el estado eclesiástico, que son fundamentalmente de tres tipos: los relativos a su número, a sus riquezas, y a los problemas que plantean sus privilegios civiles, es decir, al derecho de fuero.

En primer lugar, el número de eclesiásticos es excesivo, y ello, según Olivares, contribuye a agravar el problema de la despoblación; por tanto, debe limitarse su número "con entera seguridad de conciencia»111). También el capitán Somoza considera que su número es excesivo, lo que ocasiona su pobreza y el que no se les tenga el respeto debido a su carácter, por lo que debe pedirse al papa que disminuya el número de conventos hasta que haya sustento para todos los religiosos, y prohibirles después heredar(112). Ambos argumentos los esgrime en 1736 Fray Joseph Haro de San Clemente, quien opina que el exceso de religiosos causa la falta de 
recursos y el que deban buscarlos faltando a la observancia, y repercute negativamente en la demografía social. Por eso debe limitarse su número de acuerdo con los recursos de cada convento, y según las directrices del papa(113). Macanaz, por su parte, señala que el exceso de clero ocasiona la falta de matrimonios y de brazos para la labranza, y el número excesivo de frailes hace necesaria su reforma. Por ello, propone que se establezca un número fijo de curas en cada pueblo, que se reduzca el número de religiosos hasta dejar en cada convento un número fijo según sus institutos y que se dé igual renta a todos los conventos(114). Ensenada supone también que el exceso de religiosos es causa de la poca observancia de sus institutos como también don Lorenzo Sagarzazu, y ambos que es necesario limitarlos(115). Finalmente, el anónimo autor de la Representación hecha al Exmo. Sr. marqués de la Ensenada considera que el exceso de clero perjudica los oficios manuales y sobre todo la labranza, por lo que debe prohibirse que los labradores y artesanos puedan entrar, ellos o sus hijos, en religion, u ordenarse sacerdotes(116).

El segundo problema que cabe considerar son las riquezas del clero, y las consecuencias de su actividad económica y de la amortización eclesiástica. Ya el Conde-Duque indica que la riqueza del clero es excesiva, y su aumento constante hace necesario tomar urgentes medidas(117). Somoza y Quiroga propone que se prohiba a los eclesiásticos heredar a los seglares(118). En el XVIII, Macanaz también sugerirá que se les prohiba heredar a los seglares y recibir donaciones de rentas, que se prohiba fundar capellanias, que se les quite el exceso de bienes raices, dejando a todos los conventos igual renta, y aplicando el sobrante al tesoro público, y que se les prohiba el comercio, nombrando seglares que administren sus bienes(119). Don Lorenzo Sagarzazu sugiere el recurso al papa para que limite el exceso de bienes eclesiásticos, y que se prohiba a los religiosos y sacerdotes el comercio(120). Finalmente, don Agustín Sales reconoce a las rentas eclesiásticas, diezmos, primicias y limosnas, una función social, para el mantenimiento del culto y limosnas a los pobres, como en su origen se establecio, función que es necesario recuperar, puesto que se ha desvirtuado, volviendo a la observancia de las antiguas normasit21). Función social que también reconoce Mayáns a los bienes de espolios y vacantes, que deben aplicarse al culto y a los pobres, y no a la Cámara Apostólica(122), opinión que también mantiene el obispo Solis(123). 
Finalmente, en tercer lugar, también se consideran los problemas que plantea el fuero eclesiástico, que aparecen igualmente en los siglos XVI y $X V I I$, que en el XVIII. Primero, la exención fiscal. Olivares indica que, a pesar de cuanto contribuyen los eclesiásticos, todavía se les puede sacar más para las necesidades del erario real, para lo que debe negociarse con el papa(124). En el XVIII el problema reaparecerá planteado del mismo modo en la pluma de Ensenada, quien considera que, si bien las concesiones papales para que contribuyan los eclesiásticos son excesivas, debe sin embargo arreglarse de modo que contribuyan en una cantidad equitativa(125). También Mayáns opinará, en carta a Blas Jover, que el clero está suficientemente cargado de tributos, y no conviene cargarlo más(126). Macanaz, sin embargo, destaca en este aspecto al pedir que los eclesiásticos contribuyan por sus propiedades como los seglares, a fin de aliviar las cargas que éstos soportan, y aliviar al Tesoro(127). En cambio, la Representación hecha al Exmo. Sr. marqués de la Ensenada opina que la tributación eclesiástica debe limitarse a lo que conceda el papa, y respetarse la inmunidad fiscal(128).

En segundo iugar, aparece el problema de la inmunidad local, que Retes funda en que debe limitarse a los casos estrictamente comprendidos en su ámbito(129), y que Macanaz piensa que debe corregirse para reducir sus excesos: problema que se intentará solucionar en el acuerdo de París de 1714 y que reaparecerá en 1737(130). Y finalmente, surge el problema de la inmunidad personal de los eclesiásticos, que en todos los tiempos se desea limitar. Esta limitación se apoya en la idea de que los eclesiásticos son súbditos en cuanto a lo temporal, y por tanto el poder temporal puede castigarlos por delitos meramente temporales. Así opinan el capitán Antonio Somoza y el Condestable Fernández de Velasco(131). Mayáns fundará esta doctrina en el siglo siguiente, al afirmar que el rey ha concedido a los obispos la jurisdicción en cosas de justicia, y que por tanto tiene poder sobre la inmunidad eclesiástica (observemos que esta razón operaría tanto con respecto a la inmunidad personal como a la localy(132). Y Macanaz intentará solucionar el problema en el acuerdo de París mediante el establecimiento de tribunales del Breve en toda España, como los hay en Cataluก̃a(133). 
Relacionada con estos problemas, aparece la cuestión, repetidamente planteada, de si el rey puede emplear a los eclesiásticos en cargos civiles. Olivares y Albanel reconocen, en efecto, que el rey tiene un derecho, y el Conde-Duque recomienda que se les emplee(134). El capitán Somoza recomienda en cambio que se les encarguen funciones asistenciales, utilizando al clero como a un cuerpo de funcionarios(135). En el siglo XVIII esta última opinión tendrá continuadores en unos Discursos políticos y económicos anónimos, publicados en el mismo Semanario Erudito, y en la política oficial(136). Pero también en el XVII aparece la opinión contraria, que desaconseja el que se encomienden cargos oficiales a los eclesiásticos, sobre todo a los obispos, que con frecuencia solían ocupar los cargos de gobernadores del Consejo de Castilla. Paravicino es de esta opinión, pues cree que tales nombramientos pondrian en peligro la integridad e independencia de la jurisdicción reak137). El anónimo autor de la Representación que hizo a Felipe IV un buen vasallo también desaconseja estos nombramientos, porque impiden a los obispos desempeñar sus funciones pastorales(138); y esta opinión tendrá un continuador en Macanaz, quien señalará que los obispos, obligados a sus tareas pastorales por los Concilios, sobre todo Trento, y poco prácticos en jurisprudencia, no son aptos para cargos de consejeros(139).

Consideración aparte merecen las doctrinas episcopalistas, a pesar de estar tan desigualmente representadas en uno y otro siglo, tanto en la extensión de los textos, como en su calidad. Sin embargo, aparecen tanto en Albanel, en el XVII, como en Mayáns y en Solís, en el XVIII, una serie de rasgos comunes, básicos, de las doctrinas episcopalistas. En primer lugar, todos estos escritores reconocen la superioridad del Concilio sobre el papa, incluso en lo disciplinar. El papa tiene superioridad disciplinar sobre los obispos, opinan todos, pero su uso debe ajustarse a lo dispuesto en Trento, según Albanel(140), y debe ser guiado por el bien de la Iglesia, y no perjudicarla nunca, en lo que coinciden Albanel, Solís y Mayáns(141). Mayáns y Albanel piensan, en efecto, que las dispensas disciplinares sobre lo dispuesto en Trento no pueden quedar al arbitrio de la voluntad del papa, aunque éste tenga autoridad para dispensar en caso fundado y necesario. Todos los tres autores protestan contra la disminución de las facultades de los obispos que hace Roma, y contra las reservas en general, cuyo 
objeto es atraer a Roma el dinero de los países católicos y toda la autoridad de la Iglesia, y que dañan la disciplina, derogan lo dispuesto en los Concilios y perjudican las facultades reales. Por eso, opinan, el rey debe apoyar a los obispos para que recuperen sus derechos, o bien para que no se vean privados de ellos, según Albanel y Solís(142), y resistir las medidas que dañan la disciplina eclesiástica nacional, según Mayáns, Solís y Albanel(143). Los dos primeros basan esta afirmación en la regalía de protección de la Iglesia que tiene el rey(144), mientras que el último se funda en la autoridad del cardenal Cayetano, quien autoriza a reyes y obispos a resisitir las medidas papales que perjudiquen a la Iglesia(745): en el fondo, se trata de la misma razón. Y el medio que Mayáns y Albanel recomiendan para esta defensa es el exequatur o suplicación(146).

Hasta aquí hemos mostrado los temas regalistas que aparecen comunes en los escritos de los siglos XVI, XVII y XVIII que hemos estudiado. Sin embargo, dada la desigual calidad de unos y otros textos, y también el hecho de que hayan sido seleccionados por medio de un criterio arbitrario, cual es la publicación en el Semanario Erudito, da lugar a que haya determinados temas que aparecen en el siglo XVIII y no en los anteriores, cuales son, por ejemplo, los que hacen referencia al desigual reparto de los bienes eclesiásticos, que motiva el que haya curas incongruos que mendigan para subsistir(147), y curas ricos junto a otros mal dotados, como indica Sales(148); o el problema de los casos que salen para ser juzgados fuera de España, en los tribunales romanos, y de la jurisdicción del nuncio, problemas ambos que ocupan al autor de la Representación al Exmo. Sr. marqués de la Ensenada y a Macanaz, y el último también a Mayans(149); o bien, a nivel de pensamiento episcopalista, temas como los Concilios nacionales, la Iglesia primitiva, o visigoda, o los autores del XVI, o la jurisdicción episcopal sobre los religiosos, o el nombramiento de los beneficios, curados o no(150), temas que tan sólo aparecen en los autores dieciochescos. Pero siempre se repite la referencia a Trento como objetivo que los episcopalistas sueñan alcanzar(151).

No obstante, creemos que queda suficientemente demostrado lo que pretendíamos probar, a saber, la continuidad en los principios regalistas, y en las soluciones que se pretende dar a unos mismos problemas, entre los politicos habsbúrgicos y los borbónicos. Aún podríamos añadir un cuarto 
factor de continuidad "institucional», representado por la pervivencia de la legislación austríaca en el período borbónico, como es el caso de la Instrucción que Felipe II dio al Consejo de Cámara en 1588(152). Ello prueba que si los caracteres de la nueva época pudieron acentuar determinados factores del regalismo en el siglo XVIII, o incluso dar más peso a este aspecto en la política general de la monarquía hispánica, sin embargo la política regalista reviste un carácter similar de una a otra dinastia y desde el siglo XVI al XVIII.

\section{3) CONCLUSIONES.}

En resumen, las conclusiones generales a que puede llegarse del estudio de los textos regalistas que se publican en el Semanario Erudito son las siguientes: en primer lugar, la continuidad entre el regalismo de los siglos XVI y XVII y el del siglo XVIII, al triple nivel de los hombres que pasan del siglo XVII al XVIII para convertirse en los iniciadores del regalismo borbónico; de las obras de los teóricos y regalistas de los siglos XVI y XVII que influyen en los autores dieciochescos, y de la continuidad en los principios de la dóctrina regalista, y de las posturas y soluciones similares que se adoptan ante los problemas que pasan también de un siglo a otro. Incluso la misma publicación de textos anteriores en el Semanario Erudito es ya un factor de continuidad entre el regalismo de los Austrias y el de los Borbones.

En segundo lugar, el carácter plenamente regalista de la revista, que dedica más de la quinta parte del total de su extensión a los textos regalistas, y que refleja la totalidad de las polémicas regalistas de la primera mitad del siglo XVIII hasta el Concordato de 1753 y la jurisprudencia concordataria, a pesar de que ignora las contiendas regalistas posteriores al Concordato, o sea, las que se dan durante la segunda mitad del siglo XVIII. Y que mediante las Notas que Valladares antepone a los textos, demuestra que éstos se publican con plena conciencia de su significado, incluso-y sobre todo-en los más radicales, y que la actitud del editor es plenamen. te favorable al regalismo. 
Y finalmente, que la revista comienza dedicando un interés primordial, en principio, a los textos regalistas de tipo jurisdiccional y del siglo XVIII, para interesarse progresivamente de un modo cada vez mayor por los textos episcopalistas y por los textos regalistas de los siglos XVI y $X V I I$, hasta abandonar totalmente el regalismo jurisdiccional del siglo XVIII. La publicación de los textos episcopalistas coincide con el ascenso de los «jansenistas» al gobierno, pero se detiene a principios de 1790, precisamente cuando se consagra su dominio en los puestos clave de la vida nacional. $Y$ asi mismo, digamos que el interés que la revista siente en principio por el regalismo se hace progresivamente menos intenso, sin que jamás llegue a desaparecer del todo.

\section{NOTAS:}

(1) En este punto destacan Paul J. Guinard: La presse espagnole de 1737 à 1791. Formation et signification d'un genre (Paris, Centre de Recherches Hispaniques, 1973) que se ocupa del peso de los temas religiosos en la generalidad de la prensa; Luis Miguel Enciso Recio: Nipho y el periodismo español del siglo XVIII (Valladolid, Univ. de Valladolid, 1956), en lo que respecta a la obra de Francisco Mariano Nipho. Y M. ${ }^{a}$ Giovanna Tomsich: El jansenismo en España. Estudio sobre ideas religiosas en la segunda mitad de/ siglo XVIII(Madrid, Siglo XXI, 1973) que estudia el peso del jansenismo en El Censor y el Mercurio histórico y político.

Guinard, en su estudio general, llega a la conclusión de que Ios temas religiosos ocupan el primer lugar en la jerarquia de intereses de los periodistas (op. cit., p. 492).

(2) El título completo de la obra es: SEMANARIO ERUDITO, / QUE COMPREHENDE / VARIAS OBRAS INEDITAS, / CRITICAS, MORALES, INSTRUCTIVAS, / POLITICAS, HISTORICAS, SATIRICAS, Y JOCOSAS / DE NUESTROS MEJORES AUTORES / ANTIGUOS, Y MODERNOS. / DALAS A LUZ / DON ANTONIO VALLADARES / de Sotomayor.

En 1787 aparecieron los tomos I a VI; en 1788, los tomos VII a XV; en 1789, los tomos XVI a XXIV; en 1790, tomos XXV a XXXIII; y en 1791, el tomo XXXIV y último. Cada tomo constaba de seis entregas o "semanas"; y cada suscripción, de 18 "Semanas" ( 3 tomos), tras los cuales debia renovarse. La revista no conoció interrupciones.

Hemos utilizado la colección del Semanario que se conserva en la biblioteca del Seminario Diocesano de San Miguel, de Orihuela, encuadernada en 17 volúmenes, y clasificada con la signatura 56-B-20 a 36; cuyo uso nos ha sido franqueado con toda generosidad por el rector Revdo. D. Ildefonso Cases, y el personal del Seminario, hacia quienes deseamos hacer constar nuestra gratitud. En dicha colección falta el Prospecto con que se anunció el comienzo de la revista

Los datos sobre precios, etc. en Guinard: La presse..., 282, nota 1. 
(3) Vid. al respecto: Richard Herr: España y la revolución del siglo XVIII (Madrid, Aguilar, 1964, reimp. 1979) 158; Guinard: La presse..., 282-283; M. ${ }^{a}$ Dolores Sáiz: Historia del periodismo en España. 1. Los origenes. El siglo XVIII (Madrid, Alianza, 1983), 195-196.

(4) Cf. Las obras citadas en la nota anterior: Herr, 158-159; Guinard, 285; Sáiz, 196.

(5) Damos en apéndice la lista de las obras regalistas publicadas en el Semanario Erudito, distinguiendo entre obras de los siglos XVI y XVII y obras del siglo XVIII, y entre obras de tipo jurisdiccional y obras episcopalistas. Señalamos con un asterisco las obras dedicadas exclusivamente a la consideración de temas regalistas.

(6) La distinción entre ambas corrientes es realizada por Rafael Olaechea: Las relaciones hispano-romanas en la segunda mitad del XVIII. La Agencia de Preces. (Zaragoza, Imp. El Noticiero, 1965), pp. 15-16. Vid. también Teófanes Egido: «El regalismo y las relaciones IglesiaEstado en el siglo XVIIl», en Historia de la Iglesia en España. IV. La Iglesia en la España de los siglos XVII y XVIII (Madrid, Edica, 1979), 150.

Olaechea indica también el origen autóctono del episcoplismo español, cuya "cristalización data en el siglo XVIII desde el Dictamen, del obispo Solis» (1709), frente a la opinión tradicional que mantenía el origen extranjero del episcopalismo español y su introducción tardia: cf. Jean Sarrailh: La España ilustrada de la segunda mitad del siglo XVIII (Madrid, Fondo de Cultura Económica, 1957, reimp. 1979), 599-600.

Antonio Mestre: Ilustración y reforma de la Iglesia. Pensamiento político-religioso de $D$. Gregorio Mayans y Siscar (1699-1781) (Valencia, Ayuntamiento de Oliva, 1968), 291-292.

(7) Macanaz: Disertación histórica..., 65-69 (Semanario Erudito-en adelante S.E.-, tomo XIII).

(8) Riol: Informe..., 75-76 (S.E., tomo III) reproduce la orden real.

(9) Esta es la opinión de Portillo, quien refiere que a partir de 1726 el gobierno comienza a reunir documentos relacionados con el real patronato: cf. Mestre: La Iglesia y el Estado. Los concordatos de 1737 y 1753 , folio 31 (original mecanografiado en prensa cuyo uso debemos a la generosidad de su autor).

Ahora bien, el conjunto de las obras de Macanaz publicadas en el S.E., muestra que si bien este autor no se planteaba de modo explícito el logro del patronato universal, sí en cambio buscaba la obtención de todos los puntos que lo componian, a saber: 1) Control del mayor número posible de nominaciones para cargos eclesiásticos. 2) Percepción de espolios y vacantes, sus. pensión de pensiones, y en general, control del dinero producido por los beneficios eclesiásticos y por todas las prelacias y prebendas, y que de un modo u otro, iba a Roma. 3) Control de todos los asuntos relativos al fuero eclesiástico en sus diversos aspectos (inmunidad personal y local, exención fiscal, manos muertas, etc.) y ampliación de la jurisdicción episcopal (Cf. Olaechea, op. cit., p. 26).

Todos estos puntos aparecen en las negociaciones concordatarias a lo largo del siglo, como las aspiraciones constantes del gobierno, y son las que desde 1735 se colocan a la sombra del patronato universal cuando se plantea explicitamente como objetivo de la Junta del Real Patronato.

(10) Cf. supra, nota 8.

(11) "Tendencia exhumadora" llama Olaechea a una constante del regalismo hispánico, que consiste en la búsqueda de documentación en los archivos reales o eclesiásticos, para fundamentar el patronato real con mayor autonomia o extensión de la que Roma reconoce actualmente, o para rescatar derechos caidos en desuso. Esta tendencia comienza con los Reyes 
Católicos, quienes nombraron al efecto al Abad de Alfaro, y logra su máxima expresión con la Comisión de Archivos, que dirigirá el P. Burriel a partir de 1749. Cf. Olaechea: Las relaciones..., 43; Mestre: Despotismo e Ilustración en España (Barcelona, Ariel, 1976), pp. 144-152.

(12) Olaechea: Las relaciones..., 180.

(13) Riol alude a un informe que por orden del marqués de la Mejorada presentó al rey en 1708 , sobre la necesidad de reconocer y ordenar los archivos, y que bien pudiera ser éste: vìd. Riol: Informe..., 142 (S.E., tomo III).

(14) Fr. Joseph Haro de San Clemente: Memorial..., passim. (S.E., tomo XV).

(15) Mayans: Correspondencia..., passim. (S.E., tomo XVII). También deben encuadrarse en estas polémicas las obras del P. Burriel publicadas en los tomos II y XVI, si bien dichas obras no presentan un carácter regalista, sino llustrado.

(16) Betancurt: Derecho..., passim. (S.E., tomo XXII).

(17) La Respuesta que dio el doctor don Agustín Sales..., estudia los abusos introducidos por el clero de Valencia respecto a la primitiva dotación de las iglesias que hizo el rey Jaime el Conquistador, abusos que han desvirtuado la utilización que se debía de hacer de los bienes eclesiásticos, acaparando los sacerdotes los diezmos y primicias e imponiendo a los fieles cargas obligatorias para mantener las parroquias, cargas que sólo en las más pobres debia de haber, $y$ que son abusivas, pues para este fin se debian destinar los diezmos y primicias, y las limosnas voluntarias, que tenian este fin social y no el de enriquecer a los sacerdotes. El remedio es la equitativa dotación de todas las iglesias y el recurso a la autoridad real. Este escrito presenta un anhelo reformista en la línea mayansiana (cf. Mestre: I/ustración y reforma de la lg/esia, 237-238, que cita una carta de Mayans a Victor de la Combe, y un manuscrito autógrafo del erudito olivense, "De las fábricas de las Iglesias en el Reino de Valencia", ambos sobre el mismo tema que desarrolla la Respuesta del Dr. Sales, y partiendo de la misma base, los privilegios de Jaime l), y pretende el uso del poder real para reformar los abusos en la disciplina eclesiástica. (Respuesta que dio el Doctor Don Agustin Sales, Presbitero, Coronista de Valencia, passim. S.E., tomo XVI).

(18) En los textos no episcopalistas que acabamos de citar, consideramos que el reformismo ocupa un lugar principal, puesto que como tendremos ocasión de ver, otros textos jurisdiccionales presentan también tendencias reformistas (asi, pueden servir de ejemplo algunos de Macanaz), pero estas no ocupan el lugar principal entre las diversas preocupaciones de los autores de dichos textos.

(19) Las obras jansenizantes que aparecen en el Semanario Erudito son las siguientes:

(Anónimo): Fragmentos históricos de la vida del Excelentisimo Señor / Don Josef Patiño, Secretario que fue de Estado, Hacien- / da, Marina é Indias, en el Reynado del Señor / Don Felipe V. (S.E., tomo XXVIII, 72-118).

Benedicto XIV, P.M.: Carta de Benedicto XIV escrita al Inquisidor General / de España, sobre las obras del Cardenal de Noris, $/$ en 31 de Julio de 1748 (S.E., tomo XXX, 53-61). Se trata de la bula "Dum praeterito mense», traducida al castellano.

Antonio Alexandro Sarmiento de Sotomayor: DOCUMENTOS E INSTRUCCIONES / Que sirven, bien reflexionadas, como de guia, método y / regla para proceder con vigilante observancia en las / operaciones de todos estados. / DADAS / Por el Ilustrísimo Señor D. Fr. Antonio Alexandro Sar- / miento de Sotomayor, Obispo y Señor de la Ciudad y Obis- / pado de Mondoñedo, á su sobrino D. Juan de / Lamas Sotomayor y Sarmiento. (S.E., tomo XXVI, 118-144).

Juan de Palafox y Mendoza: JUICIO INTERIOR, / Y SECRETO DE LA MONARQUIA / PARA MI SOLO / POR EL ILUSTRISIMO SEÑOR / DON JUAN DE PALAFOX. (S.E., t. VI, 45-63). 
NOTA DEL EDITOR. (S.E., tomo VI, 63-65).

EXTRACTO / De algunas de las proposiciones, que con sumo desho- / nor de los Jesuitas, corren en algunas de las / obras del Itustrísimo Señor Don Juan / de Palafox. (S.E., tomo VI, 66-71).

NOTA DEL. EDITOR. (S.E., tomo VI, 71-72).

ORDEN DE S.M. / Aprobando la conducta del llustrisimo Señor Don / Juan de Palafox, durante el Virreynato de Nueva / España, en que manda se le abonen dos mil duca- / dos de renta / en atencion á los empeños / que habia contrahido. (S.E., tomo VI, 72-78).

NOTA DEL EDITOR. (S.E., tomo VI, 78-79).

CARTA / DEL REY NUESTRO SEÑOR, / ESCRITA A SU SANTIDAD, / interesándose en la Beatificación del llustrisimo Señor / Don Juan de Palafox. (S.E., tomo VI, 79-81). (Todas estas obras, relacionadas con Palafox, forman un solo articulo).

Manuel de Roda y Arrieta: COPIA DE LA CARTA / QUE DON MANUEL DE RODA / SIENDO AUDITOR DE ROTA EN ROMA POR LA CORONA / DE ARAGON, DIRIGIO A DON JUAN MARTIN, CON FECHA DE / PRIMERO DE JUNIO DE 1762, PARA LA EDUCACION / DE SUS SOBRINOS. (S.E., tomo $X, 225-242)$.

(Anónimo): Parecer y dictamen de un J.C. sobre el método de estu- / diar la Jurisprudencia y primeras letras. (S.E., tomo XXXIV, 160-199).

Junto con estas obras, pueden considerarse las siguientes:

Manuel Lanz de Casafonda: Del estado presente de la Literatura en España, del de las / tres Universidades mayores de Castilla, y de sus Colegios / mayores, entre dos Abates Napolitanos. Diálogo escri- / to en castellano por un Español apasionado / de la verdad. (S.E., tomo XXVIII, 119172).

Se trata de los famosos "Diálogos de Chindulza", que se publicaron por vez primera, aunque incompletos, en el Semanario Erudito. Es una obra violentamente antijesuita, pero no desde un punto de vista jansenista, sino ilustrado: las acusaciones que se hacen a los jesuitas son por su ignorancia y su monopolio de la educación.

(Anónimo): EL ZURRIAGO. / Contra varias obras de cierto Padre / de la Compañia de Jesús. (S.E., tomo I, 221-258). Esta obra, que se atribuye a don Luis de Salazar y Castro por Valladares, no es en absoluto jansenista, y las obras del padre citado se critican desde un punto de vista Iiterario; sin embargo, Herr le atribuye un carácter jansenista, por lo que hemos creído necesario aclararlo (cf. España y la revolución del siglo XVIII, 159). Los textos “jansenistas» del Semanario hacen escasa referencia directa a las polémicas "jansenistas" del siglo XVIII, y presentan escasos contenidos relativos a la espiritualidad y piedad especificamente "jansenistas", destacando sobre todo los aspectos jurisdiccionales del movimiento y el antijesuitismo. Cabe señalar que abundan en este apartado las obras de tema pedagógico.

(20) A. Mestre: "Religión y cultura en el siglo XVIII español", en Historia de la Iglesia en Es. paña. IV. La Iglesia en la España de los siglos XVII y XVIII, 678; 721-722.

(21) Mestre: op. cit. supra, 722. El doctor Mestre tuvo la gentileza de confirmar verbalmen. te esta noticia.

De todas formas, no puede establecerse en absoluto una relación automática entre las tendencias de la prensa y los grupos del poder. Recordemos que el caso más significativo de apoyo de las ideas jansenistas en la prensa (la publicación de las pastorales de Ricci y la información sobre el Sinodo de Pistoya en el Mercurio histórico y politico) se da en los años 1782 y 1787 1788 , sin que desde 1789 a 1800 aparezcan más textos jansenizantes, como afirma Tomsich 
(El jansenismo en España, 140). Ello resulta doblemente significativo por cuanto, según Mestre, los «jansenistas" cobran importancia en la Corte a partir de 1789-1790. (Mestre: Despotismo e I/ustración en España, 212; y Religión y cultura..., 678, 722), y el Mercurio era una publicación oficial, por lo que es precisamente en el periodo en que desaparece esta tendencia de sus páginas, cuando cabria esperar mayor presencia de la ideología jansenista en ellas.

(22) Herr: España y la revolución del siglo XVIII, 28.

(23) INDICE / DE LOS PAPELES / CONTENIDOS / EN LOS TRES PRIMEROS TOMOS / DE ESTA OBRA. (S.E., tomo III, 278-281). Véase las páginas 280-281.

(24) A pesar de que la correspondencia Mayáns-Jover y la carta de Mayáns a Macanaz, aparecen junto con otros textos, bajo una sola rúbrica en el indice, como ya hemos indicado, la cual totaliza 229 páginas, nosotros no hemos computado sino las 121 páginas que ocupan ambas correspondencias.

(25) Jean Sarrailh: La España ilustrada..., 600.

(26) Teofanes Egido: "El regalismo y las relaciones Iglesia-Estado en el siglo XVIII", en Historia de la Iglesia en España. IV, 141-142.

(27) NOTA DEL EDITOR, 1-11. (S.E., tomo VII).

(27 bis) lbid., p. 1.

(28) Ibid., 3.

(29) Ibid., 5.

(30) Ibid., 6. Sin embargo, circulaban secretamente obras de Macanaz en ediciones más o menos clandestinas desde mucho antes: vid. al respecto la carta de José Belluga al inquisidor general Quintano Bonifaz, de 22 de diciembre de 1759, en Carmen Martin Gaite: Macanaz, otro paciente de la Inquisición (Barcelona, Destino, 1982, 3. ${ }^{2}$ ed.) p. 471. La obra a que alude José Belluga, sobrino del famoso cardenal enemigo de D. Melchor, es la misma publicada en el S.E., tomo XIII, 3-90.

(31) NOTA DEL EDITOR, 136-137. (S.E., tomo VIII).

(32) Ibid., p. 136.

(33) Macanaz: Discurso sobre el poder que algunos doctores han querido atribuir al Papa en lo temporal, passim. (S.E., tomo VIII).

(34) Nota del editor, 136-137. (S.E., tomo VIII).

(35) NOTA DEL EDITOR, 3-4. (S.E., tomo XXV).

(36) Ibid., 3-4.

(37) Ibid., 4.

(37 bis) Asi, por ejemplo, al frente de los Auxilios para bien gobernar una monarquia católica, de Macanaz (S.E., tomo V, p. 215): "Para evitar qualquiera mala inteligencia, que se quiera dar á esta obra, ha acordado el Consejo, que se advierta al Público por medio de esta Nota, que debe leerse con aquella precaucion necesaria, para no dar mas opinion, ni credito, que el que corresponde á las especies y noticias que contienen. Añadiremos que a esta obra también se le suprimió el Auxilio XIII: "Se omite este Auxîtio por razones muy poderosas, que no le hacen digno de la Prensas (p. 279).

(38) Guinard: La presse..., 282. Herr: España y la revolución del siglo XVIII, 291.

(39) Vide supra, nota 21.

(40) Vid. Guinard, op. cit., 26. 
(41) Vid. Tratado sobre la Monarquía columbina (Una utopía antiilustrada del siglo XVIII). Edición y estudio de Pedro Alvarez de Miranda (Madrid, El Archipiélago, 1980) p. 31, nota 4.

(42) Guinard, op. cit., 31.

(42 bis) Esta continuidad ya ha sido indicada por distintos autores: vid. sobre todo Teófanes Egido: "El regalismo y las relaciones Iglesia-Estado en el siglo XVIIl", en Historia de la Iglesia en España. IV. La Iglesia en la España de los siglos XVII y XVIII, 126-134. También Rafael Olaechea: Las relaciones hispano-romanas en la segunda mitad del XVIII, 32. Por su parte, Mestre señala que la continuidad no es sólo del regalismo, sino también del ultramontanismo: La Iglesia y el Estado..., f. ${ }^{\circ} 2$. Vid. también Ilustración y reforma de la lglesia, 358-368.

(43) Luis de Salazar y Castro: Discurso politico sobre la flaqueza de la monarquia española en el reynado de D. Carlos Segundo, y valimiento del conde de Oropesa. Año de 1687. Por don Luis de Salazar y Castro. (S.E., tomo II). Valladares pone en duda que Salazar y Castro sea verdaderamente el autor de esta obra, en una NOTA, pp. 129-130, a pesar de que comunmente se le daba.

(44) Macanaz: "Advertencia del autor", en: Explicación juridica e historica..., 4-6. (S.E., tomo $(X)$.

(45) Riol: Informe..., 139-143. (S.E., t. III). Id.: Representacion sobre el Patronato real..., 82-84 (S.E., tomo VI).

(46) Martin Gaite: Macanaz, otro paciente..., 261.

(47) Vide supra, nota 8.

(48) En este sentido, Riol cita una serie de esfuerzos que se hicieron en el siglo XVII para la ordenación de determinados archivos en el sentido que él pretende poner de relieve: así el de Ordenes en 1690 por don Joseph Antonio Severino; el de Cruzada en 1699 por D. Bernardo Muñoz Tobar, etc. En cuya linea se inserta su esfuerzo, sin olvidar que la investigación que llevaba a cabo era continuación de la iniciada en 1688 por el marqués de Mejorada.

(49) Martin Gaite: Macanaz, otro paciente..., 38-40.

(50) Francisco de Solís: Dictamen que de orden del rey..., 250-255. (S.E., tomo IX).

(51) Teófanes Egido: “El regalismo...", 128; Rafael Olaechea: Las relaciones hispanoromanas..., 39; Mestre: Ilustración y reforma de la Iglesia, 260.

(52) Macanaz: Representación que hice y remit' desde Lieja..., 184-185 (S.E., t. VII). Mayáns: Observaciones al Concordato de 1753, 106-107, (S.E., t. XXV) y 107-108 (tomo XXVI del Semanario).

Sobre este sistema, puede verse: Instrucción que el Señor Rey Don Felipe II dio al Consejo de Cámara en 6 de Enero de 1588, 11-14. (S.E., tomo XXX).

(53) Riol: Informe..., 89-110, sobre los Reyes Católicos, y 201-202. (S.E., t. III). Id.: Representación sobre el Patronato real..., 90-94. (S.E., tomo VI).

(54) Solis: Dictamen..., 250-255 (S.E., t. IX). Vide supra, nota 50.

(55) Mayáns: Observaciones..., 121-125. (S.E., t. XXV).

(56) Solís: Dictamen..., 262 (S.E. t. IX). Mayáns: Observaciones..., 147-148, 149-150, 152-156, 281 (S.E., t. XXV).

(57) Haro: Memorial..., 66-67, 75-78, 80-81, 95-96, et al. (S.E., tomo XV).

(58) Mayáns: Correspondencia..., 124, 143, 148, 154-155, 166, 178. (S.E., tomo XVII). 
(59) Betancurt: Derecho de las iglesias metropolitanas y catedrales de Indias..., passim. (S.E., tomo XXII). Betancurt acumula citas de un modo reaimente desaforado, citando a muchos otros autores antiguos y contemporáneos, además de los mencionados, como v.g. Mariana, SoIórzano Pereira, el P. Acosta, Antonio de León Zapata, etc.

Retes: Conveniencia y concordia de ambas jurisdicciones en materia de inmunidad local..., 3-18 (S.E., t. XXI).

(60) Macanaz: Representación que hice y remiti desde Lieja.., pp. 172-176. (S.E., tomo VII).

(61) Mayáns: Correspondencia..., 107, 131, 144-145, 170-171, 172-175, 182 (S.E., tomo XVII) y Observaciones, 104, 183-185 (S.E., tomo XXV).

(62) Mayáns: Correspondencia..., 187, 206. (S.E., t. XVII).

(63) Quevedo: Advertencias o commentos. Disculpando los desabrimientos de esta carta, en Fernando el Católico: Carta del Rey Católico al conde de Rivagorza..., 264-265.

(64) Fr. Hortensio Félix Paravicino: Proposición que hizo... al rey Felipe IV, 181 (S.E., $t$. XXVIII). Retes: Conveniencia y concordia..., $57-58$ y 82 (S.E., t. XXI). Albanel: Parecer, 208, 209, 217 (S.E., tomo XIV).

(65) Macanaz: Representación que hice y remiti desde Lieja..., 161-162. (S.E., t. VII), y especialmente el Discurso sobre el poder que algunos doctores han querido atribuir al Papa en lo temporal, (S.E., t. VIII), íntegramente dedicado a este temayid. expresamente pp. 138 y 142. Mayáns: Observaciones..., 27 (S.E., t. XXVI).

(66) Macanaz: Discurso sobre el poder..., 138, 146-147, 159-160. (S.E., tomo VIII).

(67) Garcerán Albanel: Parecer..., 208, 209, 217 (S.E., t. XIV). Notemos que el origen divino de la potestad real independiente de la pontificia espiritual, y facultada a resistir las medidas romanas que ataquen a los derechos reales y la disciplina eclesiástica, puesto que "no era justo permitir á un Papa destronar Reyes, y despedazar la Iglesia de Dios" (pp. 214-215), se formulan 60 años antes de que Bossuet diera forma al Primer Principio del Clero Galicano. (Aunque la carta está fechada en 1635, esta fecha es errónea, porque el arzobispo Albanel murió en 1625. Quizá sea ésta la data cierta). Mayáns: Observaciones..., 148, 150 (S.E., t. XXV), y 27, 29-30 (S.E., t. XXVI). Macanaz: Discurso sobre el poder..., 139-142, 146 (S.E., t. VIII). Del mismo autor: Representación que hice y remiti desde Lieja..., 171-176, 184-185 (S.E., t. VII) y Explicación juridica e histórica..., 43, (S.E., t. IX).

(68) Macanaz: Auxilios para bien gobernar..., 296 (S.E., t. V).

(69) Macanaz: Auxilios..., 255-256 (S.E., t. V), y Representación que hice y remiti desde Lieja..., 171-173, 174-176. (S.E., tomo VI1). Mayáns: Observaciones..., 25-27, 29-30, 31-35 (S.E., t. XXVI). Somoza y Quiroga: Unico desengaño..., 246, 249 (S.E., t. XI). Juan Fernández de Velasco: Carta... al Papa Clemente VIII..., 266-267 y 269-270 (S.E., t. XXIX). Somoza lo da a entender al sugerir que el rey castigue a los clérigos defraudadores, y que disminuya el numero de clérigos y religiosos de manera que todos tengan congrua suficiente, prohibiéndoseles luego heredar rentas y bienes raices; y al proponer que cada obispado cree un hospital para dar asilo y asistencia, y también trabajo, a los enfermos, tullidos y pobres, y que el clero se encargue del control de viajeros, asignándoles de este modo funciones propias de un cuerpo funcionarial.

Por su parte, el virrey Fernández de Velasco se cree con derecho a desterrar a un vicario del arzobispo de Milán, Federico Borromeo, por una causa civil, como es uturbador de la quietud pública", con intervención de soldados, y haciendo caso omiso de la inmunidad personal de los eclesiásticos, por tratarse de competencia exclusiva de la jurisdicción temporal. 
(70) Fernando el Católico: Carta... al conde de Rivagorza..., 262, 262-263, (S.E., t. I). Quevedo: Advertencias o commentos, 263-264, 264-265, 265 (S.E., t. I). Albanel: Parecer, 217 (S.E., t. XIV). Betancurt: Derecho de las Iglesias metropolitanas y catedrales de las Indias..., 26 (S.E., t. XXII).

(71) Solís: Dictamen..., 258-259 (S.E., t. IX). Riol: Representación sobre el patronato real..., 85-86 (S.E., t. VI), referida a los Reyes Católicos, en Informe..., $90-91$ (S.E., t. III), el modo de proceder de dichos reyes, ibid., 93-94.

(72) Felipe 11: Instrucción... a Don Diego de Covarrubias, obispo de Segovia, presidente de Castilla, 3-4 y 6 (S.E., t. XXX).

Felipe II encarga al presidente de Castilla:

Lo primero que quiero advertiros es, por cumplir con mi obligación, encomendaros al servicio de nuestro Señor, y que en la Corte y fuera de ella haya mucha cuenta con esto. Para ello importa el buen exemplo que vos dareis, que será el que habéis dado hasta aqui, y se vele en el gobierno de todo; y en la Corte saber como cumplen los ministros con su obligación, y será bien traer advertidos á los Alcaldes de Corte, que no sean remisos en lo que les toca. (pp. 3-4).

De ahi que opine que sea conveniente averiguar si los consejeros o ministros de justicia faltan en algo, porque ello sería un gran inconveniente que convendria atajar con un castigo ejemplar, y ello "seria parte de la enmienda venidera, y convendria tambien para el descargo de mi conciencian. (p. 6).

Macanaz: Auxilios para bien gobernar una monarquia católica, 225-228, 228, 229-232 (El rey tiene como primer cuidado conservar y defender la religión, por ser fuente de orden público, unidad y obediencia; debe evitar la multitud de opiniones sobre religión, convocando concilios para remediarlas; $y$ debe cuidar la predicación a fin de que se dé buena enseñanza al pueblo que fundamente la observancia y pureza de la religión); 275-276 (se trata del Auxilio XI: "Castigo de los błasfemos, quán útil es al Estado); y 296 (castigo de las adúlteras y los amancebamientos). Todo esto en S.E., t. V.

(73) Betancurt: Derecho..., 26-27 (S.E., t. XXII). Albanel: Parecer..., 214-215, 215-216, 217 (S.E., t. XIV). Solis: Dictamen..., 258-259 (S.E. t. IX). Mayáns: Observaciones..., 264-265 (S.E., t. XXV) y 26, 100-101 (S.E., t. XXVI). Haro: Memorial..., 51-52, 61-62 (S.E., t. XV): puesto que el fin del Memorial del P. Haro es instar al rey a la aplicación de la bula Apostolici Ministerii, para la reforma de los religiosos, ya lleva implicita la suposición para el rey de la regalia de protección de la disciplina eclesiástica.

Macanaz: Auxilios..., 296 (S.E., t. V). Vid. también nota 72 supra, el deber que tiene el rey de guardar la pureza de la observancia religiosa entre sus súbditos. Del mismo autor: Representación que hice y remiti desde Lieja..., 170, 174-176, 182-185, 194-195, 195-197 (S.E., tomo VII). Id. Avisos políticos..., 221, 233 (S.E., t. VIII).

Ensenada: Representacion hecha al Sr. D. Fernando el VI..., 278 (S.E., tomo XII).

(74) Mayáns: Observaciones..., 264-265 (S.E., t. XXV); 26, 31-35 (S.E., tomo XXVI).

(75) Solis: Dictamen..., 258-259, 260 (S.E., tomo IX).

(76) Macanaz: Auxillios..., 220, 221, 255-260, 296 (S.E., t. V). Id.: Representación que hice y remiti desde Lieja..., 171-173, 173-176, 182-184, 184-185 (S.E., t. VII). Id.: Avisos politicos..., 221, 232-233 (S.E., t. VIII).

(77) Albanel: Parecer..., 215-216, 217 (S.E., t. XIV).

(78) Haro: Memorial..., 51-52, 61-62 (S.E., t. XV).

(79) Betancurt: Derecho..., 60-61, 63-65, (S.E., t. XXII). Puede verse este tema a lo largo de toda la obra. 
(80) Fernando el Católico: Carta... al conde de Rivagorza..., 262-263 (S.E., tomo I).

(81) Riol: Representación sobre el Patronato real.., $85-86$ (S.E., tomo VI).

(82) Mayáns: Correspondencia.., 202 (S.E., tomo XVII). Mayáns dice al respecto:

La doctrina de Vazquez Menchaca de que los Principes tienen el derecho de las elecciones en calidad de Soberanos, y que este derecho se puede considerar como natural; es detestable, y merece censura teológica. (...) la comparación con Covarrubias odiosa. (Mayans a Blas Jover, 15-X-1746).

(83) Betancurt: Derecho..., 26 (S.E., tomo XXII). Mayáns: Correspondencia..., 124, 175-176 (S.E., t. XVII), y Observaciones.., 56-59, 92-95, 136, 139-140 (S.E., t. XXV). Riol: Representación sobre el Patronato real, 85-86 (S.E., t. VI). Gándara: Informe reservado..., 47-48 (S.E., tomo Xil).

(84) En efecto, aunque Betancurt reconoce al patronato su origen tanto en los derechos de fundación y dotación, como en la soberania real, y en concesiones apostólicas, son éstas las que para Betancurt determinan la naturaleza del patronato, y sobre todo (puesto que habla de las Indias), la bula de Alejandro VI, de 1501, al disponer que se dé a las iglesias los diezmos, salvo los dos novenos reservados al rey, lo que llevaria a que siendo los bienes de fundación eclesiásticos, fuera el patronato sobre las iglesias de naturaleza eclesiástica (Derecho..., 63-65). Pero por otra parte, el derecho de presentación es siempre en origen cesión pontificia, por lo que su ejercicio debe ajustarse a las normas canónicas (id., p. 61). (S.E., tomo XXII).

(85) Mayáns: Correspondencia..., 175-176 (S.E., t. XVII), y Observaciones..., $56-59$ (fundación, dotación, edificación) 92-95 (conquista). (S.E., tomo XXV).

(86) Vid. supra, nota 81.

(87) Gándara: Intorme reservado..., 7-10 (S.E., t. XII).

(88) Fernando el Católico: Carta... al conde de Rivagorza..., 259-260 y 262 (S.E., t. !). Quevedo: Advertencias o commentos, 264 (S.E., t. I). Macanaz: Explicación juridica e histórica de la consulta que hizo el Real Consejo de Castilla al Rey nuestro Señor, passim (S.E., tomo IX).

(89) Gándara: Informe reservado..., 7-10 y 18 (S.E., t. Xfi).

(90) Fernando el Católico: Carta... al conde de Rivagorza.., 260-261 y 262-263 (S.E., t. I).

(91) Retes: Conveniencia y concordia..., $77-79$ (S.E., t. XXI). Albanel: Parecer, 215-217 (S.E., tomo XIV).

(92) Macanaz: Discurso sobre el poder..., 159-160 (S.E., tomo VIII).

(93) Vid. Gándara: Informe reservado..., 53-55 (S.E., t. XII). Mayáns: Observaciones..., 264265 (S.E., tomo XXV.

(94) Riol: Informe..., 111.113, 145-146 (S.E., t. III), y Representación sobre el Patronato real..., passim. (S.E., tomo VI). Mayans: Correspondencia..., 148, 154-155, 166 (S.E., tomo XVII), y Observaciones..., 65-68 y 73: un ejemplo práctico en págs. 197-202 (S.E., t. XXV).

(95) Retes: Conveniencia y concordia..., passim. (S.E., tomo XXI).

(96) Fernando el Católico: Carta... al conde de Rivagorza..., 259-260 y 262 (S.E., tomo I). Quevedo: Advertencias o commentos, 263-264, 264-265, 267-268 (S.E., t. I). Riol: Informe..., 90-91, 94 (S.E., tomo III).

(97) Riol: Informe..., 95-96, 101, 110, y en general, el reformismo se indica como objetivo principal de la actuación regalista de los reyes, que se narra por extenso: págs. 86-110 (S.E., tomo III). 
(98) Felipe II: Instrucción... al Consejo de Cámara..., 12-13 (S.E., tomo XXX). Olivares: Instrucción que se dio al señor Felipe Quarto..., 167 (S.E., t. XI).

(99) Betancurt: Derecho..., passim. (S.E., t. XXII).

(100) Macanaz: Representación que hice y remiti desde Lieja..., 194-197 (S.E., tomo VII).

(101) Riol: Representación sobre el patronato real..., 86 (S.E., tomo VI). Mayáns: Observaciones..., 106-115 (S.E., tomo XXVI), y Correspondencia..., 230 (S.E., tomo XVII).

(102) Riol: Representación sobre el Patronato real..., 95-96 (malas provisiones romanas que originan mal gobierno de las almas), 86 (el derecho de patronato permite al rey nombrar varones virtuosos), en S.E., tomo VI. Del mismo autor, Informe..., 92-93, 96 (malas provisiones y daño a las almas en tiempo de los Reyes Católicos) en S.E., tomo III. Mayáns: Observaciones..., 103104 (malas provisiones romanas que originan mal gobierno de las almas), 120, 126, 250, 267 (S.E., t. XXV), 114-115 (S.E., t. XXVI): importancia de escoger los mejores para obispos y curas de almas, a fin de procurar su buen gobierno. Betancurt: Derecho..., 38-39, 41-42, 43 (necesidad de proveer los mejores para el buen gobierno de la Iglesia), $92-94$ (las malas provisiones originan indisciplina y largas vacantes), 97 (los malos provistos extraen el dinero de las iglesias en beneficio propio), también ibid., 99-100 (S.E., t. XXII).

(103) Betancurt: Derecho..., 94 (largas vacantes y daño que producen en la falta de sacramentos, dispensas, indisciplina, etc.), 97 (único medio eficaz de evitarlas) (S.E., tomo XXII).

(104) Mayáns: Observaciones..., 112 (S.E., t. XXVI). Macanaz: Representación que hice y remiti desde Lieja..., p. 170 (S.E., t. VIi): inconveniente de nombrar obispos para presidentes del Consejo, por la obligación de atender a sus ovejas en que están). Felipe II: Instrucción... a/ Consejo de Cámara..., 12 (S.E., t. XXX). En el mismo sentido que Macanaz se expresa también en el siglo XVII el anónimo autor de una REPRESENTACION / que hizo al Rey Don Felipe IV un buen vasallo, después que / S.M. separó de su privanza al Conde-Duque de Olivares..., 263-264 (S.E., tomo XIX; vide infra, nota 138 ).

(105) Macanaz: Representación que hice y remiti desde Lieja..., 184-185 y 194-195 (S.E., t. VIi). Felipe II: instrucción... al Consejo de Cámara..., 13 (S.E., t. XXX).

(106) Betancurt: Derecho..., 97 y 99-100 (S.E., t. XXII). Salazar y Castro: Discurso politico..., 132, 136-137 (S.E., t. 18). Albanel: Parecer, 212-213 (S.E., t. XIV).

(107) Mayáns: Observaciones..., 109-111, 113-115, 186, 239, 283 (S.E., t. XXV) y 11, 102, 104105 (S.E., t. XXVI). Solis: Dictamen..., 214, 222-225, 227-229, 230-232, 233-235, 247 (S.E., t. IX). Riol: Representación sobre el Patronato real..., $95-96$ (S.E., tomo VI). Como vemos, las preocupaciones económicas ocupan un lugar preferente en la atencion de nuestros regalistas.

(108) Macanaz: Disertación histórica..., 65-69 (S.E., t. XIII) ofrece el articulado de dicho acuerdo e indica que las únicas dificultades que se suscitaron fueron al defender la Dataria las rentas que sacaba de España, objeciones a las que se respondió a través de Joseph Molines.

(109) Betancurt: Derecho..., 51-52, 84-85 (S.E., t. XXII). Riol: Representación sobre el Patronato real.., 86, 95-96 (S.E., t. VI). Mayáns: Observaciones..., 115-116 (S.E., t. XXVI). Vicente Cangas Inclán: Carta sobre el origen y serie de las Cortes..., 260 (S.E., tomo III).

(110) Felipe 11: Instrucción... al Consejo de Cámara..., 11-13 (sistema de información y consulta para cargos eclesiásticos), 16 (que no se consulte a pretendientes en la Corte, sino que vuelvan a sus casas): en S.E., tomo XXX. Betancurt: Derecho..., 71-72, 72-74, 75 (S.E., t. XXII) Riol: Representa- 
ción sobre el patronato real..., 95-96 (S.E., t. VI): el nombramiento por el rey evitará que los pretendientes tengan que acudir a Roma. Mayáns: Observaciones..., 116-117 (S.E., t. XXVI).

(111) Olivares: Instrucción que se dió al señor Felipe Quarto..., 223 (S.E., tomo XI).

(112) Somoza y Quiroga: Unico desengaño..., 249 (S.E., t. XI).

(113) Haro: Memorial..., passim. (S.E., t. XV). La reducción del número de religiosos a los habitantes que cada convento pueda mantener con sus recursos habituales, siguiendo las disposiciones de la bula Apostolici Ministerii, es el tema central del Memorial de Fr. Joseph Haro de San Clemente.

(114) Macanaz: Representación que hice y remití desde Lieja..., 171-177 y 182-184 (S.E., t. VIl). También Avisos politicos..., $231-233$ (S.E., t. VIII), y Auxilios..., 255-260 (S.E., t. V).

(115) Marqués de la Ensenada: Representación hecha al Sr. D. Fernando el VI..., 278 (S.E., tomo XII). Lorenzo Sagarzazu: Reglas y documentos dados al Sr. rey D. Fernando el VI..., 231-232 (S.E., tomo XIII).

(116) (Anónimo): Representación... al Emo. Sr. Marqués de la Ensenada..., 10-13 (S.E., t. $\mathrm{XV)}$.

(117) Olivares: Instrucción que se dio al señor Felipe Quarto..., 166-167 (S.E., tomo XI).

(118) Somoza y Quiroga: Unico desengaño..., 249 (S.E., t. XI).

(119) Vid. supra, nota 114.

(120) Lorenzo Sagarzazu: Reglas y documentos dados al Sr. rey D. Fernando el VI..., 231 (S.E., tomo XIII).

(121) Agustín Sales: Respuesta que dió el Doctor Don Agustín Sales..., passim. (S.E., tomo $X V I)$.

(122) Mayáns: Observaciones..., 181-204 y 277 (S.E., t. XXV): todo lo referente a espolios y frutos de sedes vacantes y a sus debidos destinos y apropiación por la Cámara Apostólica.

(123) Solís: Dictamen..., 223-225 (S.E., tomo IX).

(124) Olivares: Instrucción que se dió al señor Felipe Quarto..., 167 (S.E., tomo XI).

(125) Ensenada: Representación... al Sr. D. Fernando el VI..., 278 (S.E., tomo XII).

(126) Mayáns: Correspondencia..., 203, 207-208 (S.E., tomo XVII).

(127) Macanaz: Avisos politicos..., 231 (S.E., t. VIII); id.: Representación que hice y remiti desde Lieja..., 171-173, 174-176 (S.E., tomo VII); id.: Auxilios..., 255-256 (S.E., tomo V).

(128) (Anónimo): Representación hecha al Emo. Sr. Marqués de la Ensenada..., 273 (S.E., t. XIV).

(129) Joseph Fernández de Retes: Conveniencia y concordia..., passim. (S.E., tomo XXI).

(130) Macanaz: Auxilios..., 240 (S.E., t. V); del mismo autor: Disertación histórica..., 65-69 (S.E., t. XIII), en donde ofrece el articulado del acuerdo de 1714: sobre inmunidad local, articulo 11. El Concordato de 1737, reproducido en Historia de la Iglesia en España. IV. La Iglesia en la España de los siglos XVII y XVIII, apéndice II, pp. 797-802.

(131) Fernández de Velasco: Carta... al Papa Clemente VIII..., 266-267 (S.E., tomo XXIX). Somoza y Quiroga: Unico desengaño..., 229 (S.E., tomo XI). 
(132) Mayáns: Observaciones..., 31-35 (S.E., tomo XXVI).

(133) Macanaz: Disertación histórica..., 65-69 (S.E., t. XI1I): el establecimiento de tribunales del Breve, art. ${ }^{\circ} 14$.

(134) Olivares: Instrucción que se dió al señor Felipe Quarto..., 168 (S.E., tomo XI). Albanel: Parecer, 208-209 (S.E., tomo XIV).

(135) Somoza y Quiroga: Unico desengaño..., 246 (S.E., tomo XI).

(136) (Anónimo): DISCURSOS / POLITICOS Y ECONOMICOS / PARA QUE LA ESPAÑA SE RESTABLEZCA DE LA SITUA- / CION EN QUE SE HALLA, É IGUALE EN OPULENCIA / Á LAS MAYORES MONARQUIAS / DE EUROPA.

Publicado en S.E., tomo XXIV, pp. 3-71. Pide, como Somoza, que el clero se encargue del control de viajeros (Vid. nota 69, supra).

Lo relativo a control de viajeros, 24-25.

El discurso III: "De la multitud de pobres" (pp. 16-20) alaba y recomienda la solución de los hospicios de pobres (en concreto los de Madrid), y recomienda el control de pobres e incluso de los peregrinos a Santiago, y el trabajo obligatorio.

El escrito no está fechado, pero debe datarse entre 1772 y 1776 (probabiemente hacia esta última fecha), pues alude al arzobispo "que fue de Santiago", Bartolomé de Raxoy (muerto en 1772), y habla de que Dios quiera «que en el proxîmo (año) de 77 no tengamos que llorar, á no haber una gran cosecha en el venidero Agosto...".

Sobre la politica borbonica al respecto, vid. Antonio Dominguez Ortiz: Sociedad y Estado en el siglo XVIII español (Barcelona, Ariel, 1976), p. 371 y nota 25, 341-344; del mismo autor: Las clases privilegiadas en el Antiguo Régimen, (Madrid, Itsmo, 1979, 2. ${ }^{a}$ edic.), p. 232. Y también: Richard Herr: España y la revolución del siglo XVIII, 28.

(137) Fr. H. F. Paravicino: Proposición..., 180-181 (S.E., tomo XXVIIl).

(138) (Anónimo): REPRESENTACION/que hizo al Rey Don Felipe IV. un buen vasallo, despues que / S.M. separó de su privanza al Conde-Duque de Olivares, / sobre que se le oyese en justicia, para que siendo ciertos los / hechos que se le atribuian, le impusiese mayor castigo, y no/ siendolo le honrase y favoreciese con las mismas o ma- / yores muestras de afecto y benevolencia que / hasta alli.

Publicado en S.E., tomo XIX, pP. 257-270.

Se trata de un alegato contra el Conde-Duque y su política, datable quizá hacia 1643. La opinión contraria a conferir cargos civiles a los obispos, en las páginas 263-264.

(139) Macanaz: Representación que hice y remiti desde Lieja..., 170 (S.E., tomo VII).

(140) Albanel: Parecer, 205-207 (S.E., tomo XIV).

(141) Albanel: Parecer, 216-217 (S.E., tomo XIV7. Mayáns: Observaciones..., 262-263, 267268 (S.E., t. XXV). Solis: Dictamen..., 229-230 (S.E., tomo IX).

(142) Solís: Dictamen..., 260 (S.E., tomo IX). Albanel: Parecer, 215-216 (S.E., tomo XIV).

(143) Albanel: Parecer, 217 (S.E., tomo XIV). Solis: Dictamen...258-259 (S.E., tomo IX). Mayáns: Observaciones..., 264-265 (S.E., tomo XXV).

(144) Solis: Dictamen..., 258-259 (S.E., tomo IX). Mayáns: Observaciones..., 26, 100-101 (S.E., tomo XXVI). 
(145) Albanel: Parecer, 214-215 (S.E., tomo XIV).

(146) Albanel: Parecer, 215-216 (S.E., tomo XIV). Mayáns: Observaciones..., 264-265 (S.E., tomo XXV).

(147) Macanaz: Avisos politicos..., 233 (S.E., tomo Vill). Id.: Representación que hice y remiti desde Lieja..., 184-185 (S.E., tomo VII). (Anónimo): Representación... al Emo. Sr. Marqués de la Ensenada..., 18-19 (S.E., tomo XV).

(148) Agustin Sales: Respuesta que dió el Doctor Don Agustín Sales..., 228, 229-230 (S.E., tomo $X \mathrm{VI})$.

(149) (Anónimo): Representación... al Emo. Sr. Marqués de la Ensenada..., 17-18 (S. E., tomo XV). Macanaz: Auxilios, 221 (S.E., t. V), y Disertación histórica..., 65-69 (S.E., t. XIII): sobre los pleitos que iban a tribunales romanos y jurisdicción del nuncio, artículos 6,7 y 8 . Mayáns: $O b$ servaciones..., 277-284 (S.E., t. XXV): apelaciones a Roma; y pp. 284-288 (S.E., t. XXV) y 3-9, 12-13 (S.E. t. XXVI): sobre la jurisdicción del nuncio.

(150) Todos estos temas aparecen constantemente en los autores episcopalistas del siglo XVIII cuyas obras publica el Semanario Erudito, salvo los asuntos relativos al nombramiento de beneficios "cum cura et sine cura", que no aparecen en el Memorial de Fr. Joseph Haro de San Clemente.

(151) Mayáns: Observaciones..., 62-63, 115 (S.E., t. XXVI). Solis: Dictamen..., 250-255 (S.E., tomo IX). Haro: Memorial..., 51-52, 54-55, 58-59, 70, 73 (S.E., t. XV). Albanel: Parecer, 206-208, 210211 (S.E., t. XIV).

(152) En efecto, cuando con motivo de la firma del Concordato de 1753, Fernando VI formo la Instrucción que deberá observar mi Real Consejo de la Cámara en el uso y práctica del Concordato, de 17 de julio de 1753, ordenaba "que en los informes y consultas se observara lo dispuesto por la Instrucción que el 6 de enero de 1588 dió a la Cámara el rey don Felipe Il». También Fernando VI renovo algunas otras de las medidas que Felipe II arbitra en esta Instrucción, como las relativas a que se pidiera informes a los obispos, abades, priores, superiores, deanes de los cabildos, etc. para conocer exactamente el número y calidad de todas las piezas eclesiásticas del reino, formando relaciones de todas ellas; e incluso el encargo de que los pretendientes vuelvan a sus casas y solo se provean las peticiones hechas por escrito (Olaechea: Las relaciones hispano-romanas..., 152 y 166). Como vemos, doscientos años después de Felipe II, en circunstancias que reclaman una nueva ordenación de la administración patronal (muy aumentada ahora con todos los beneficios que antes eran de provision papal), se repiten las medidas arbitradas por el Prudente.

Por otra parte, el sistema de consultar la Cámara al rey los candidatos, que instituyó Felipe Il, perduró a lo largo de los siglos XVII y XVIII, pues había sido incluido como ley en la Nueva Recopilación (A. Dominguez Ortiz: Las clases privilegiadas..., 217-219; y Sociedad y Estado en el siglo XVIII español, 369-370). 


\section{A PENDICE}

\section{LISTA CRONOLOGICA DE LAS OBRAS REGALISTAS PUBLICADAS EN EL SEMANARIO ERUDITO}

Ofrecemos a continuación la lista cronológica de las obras publicadas en el Semanario Erudito que presentan tendencias regalistas, según la fecha en que fueron escritas, y divididas en dos apartados, correspondiendo el primero a las obras de los siglos XVI y XVII, y el segundo a las del XVIII. Dentro de cada apartado distinguiremos entre obras de carácter jurisdiccional y obras episcopalistas.

A) Obras regalistas de los siglos XVI y XVII.

a) Obras de tipo jurisdiccional.

*1) Fernando el Católico y Francisco de Quevedo: CARTA / QUE REMITIO / EL REY CATOLICO, I AL CONDE DE RIVAGORZA, / SU VIRREY EN NAPOLES. ADVERTENCIAS, O COMMENTOS, / Disculpando los desabrimientos de es- / ta Carta. / POR /D. FRANCISCO DE QUEVEDO Y VILLEGAS, / Remitido uno, y otro al Excelentísimo Señor Duque / de Osuna, siendo Virrey de Nápoles. Publicado en S.E., tomo l, páginas 259-270.

*2) Felipe II: Instrucción que el Señor Rey Don Felipe II. dió al Con- I sejo de Cámara en 6 de Enero de 1588. Publicado en S.E., tomo XXX, páginas 9-19.

3) Felipe II; Instrucción del Señor Don Felipe II á Don Diego / de Covarrubias, Obispo de Segovia, Presi- / dente de Castilla. Publicado en S.E., tomo XXX, páginas 3-8.

4) Felipe II: Carta del Señor Rey Don Felipe II. escrita al Principe / de Melitó, su Virrey, y Capitán General en Cataluña, / avisandole de las prevenciones que se han de hacer para / ladefensa de Cataluña en la Costa de mar y fronteras de / Francia. Otra al Embaxador de Roma, sobre que dili- / gencie con su Santidad, que los Embaxadores que tienen / los Diputados de Cataluña en aquella Corte sobre la / competencia con el Santo Oficio, salgan / de ella. Publicado en S.E., tomo XXVIII, páginas 212-221. 
*5) Juan Fernández de Velasco: Carta del Condestable Don Juan Fernández de Velasco, I al Papa Clemente VIII. habiendole excomulgado, I siendo Virrey y Capitan General de Milan / año de 1599. Publicado en S.E., tomo XXIX, páginas 265-280.

6) Conde-Duque de Olivares: INSTRUCCION / QUE SE DIO / AL SEÑOR FELIPE QUARTO, / SOBRE / MATERIAS DEL GOBIERNO DE ESTOS REYNOS Y SUS / AGREGADOS. Publicado en S.E., tomo XI, páginas 162-224.

7) Fr. Hortensio Félix Paravicino: Proposicion que hizo de doce sugetos para Presidente de / Castilla el Maestro Hortensio Felix Palavicino (sic) al Rey / Felipe IV. año de 1626. Publicado en S.E., tomo XXVIII, páginas 179-184.

*8) Luis Betancurt y Figueroa: DERECHO / DE LAS IGLESIAS METROPOLITANAS / y Catedrales de las Indias: / SOBRE / que sus Prelacias sean provehidas en los Capitulares de / ellas y naturales de sus Provincias. / AL REY NUESTRO SEÑOR, / EN SU REAL Y SUPREMO CONSEJO DE LAS INDIAS, / POR / el Doctor Don Luis de Betancurt y Figueroa, Chantre de la Santa Iglesia de San Francisco de Quito, en las / Provincias del Perú. Publicado en S.E., tomo XXII, páginas 23-109.

*9) Ferrante y Brancia: Voto del Regente Ferrante Brancia, fundando que la al- / ternativa en lo Eclesiástico, comprehende el caso de va- / cante por traslación, como el de muerte. Publicado en S.E., tomo XXXIV, páginas 199-220.

*10) Joseph Fernández de Retes: CONVENIENCIA / y concordia de ambas jurisdicciones en materia de inmunidad / local, que no ha lugar en los condenados por sentencia pa- / sada en juzgado á servicio personal de galeras / ó presidio / PRACTICA / de la l.9. tit. 24. lib. 8. Regiae Copilationis versic. penult. I en dos causas que están pendientes en el Tribunal Ecle- $/$ siástico, y pedida remision al seglar, interpuesto el re- / curso de conocer, $y$ proceder ante los señores Presi- / dente y Oidores. / POR / EL DR. D. JOSEPH FERNANDEZ DE RETES, / Fiscal de S.M. en Sala del Crimen de esta Corte, y Chan- I cillería de Valladolid. Publicado en S.E., tomo XXI, páginas 3-98.

11) Antonio Somoza y Quiroga: UNICO DESENGAÑO, / Y PERFECTO REMÉDIO / DE LOS MENOSCABOS DE LA CORONA / DE CASTILLA, Y GENERAL ALIVIO DE TODOS / SUS VASALLOS. / DADO / AL SEÑOR REY DON CARLOS II. ${ }^{\circ}$ / POR EL CAPITAN / DON ANTONIO DE SOMOZA $Y$ QUIROGA / EL AÑO DE 1680. Publicado en S.E., tomo XI, páginas 225-256. 
12) Luis de Salazar y Castro: DISCURSO POLITICO / SOBRE LA FLAQUEZA DE LA MONARQUIA / ESPAÑOLA EN EL REYNADO DE D. CARLOS / SEGUNDO, Y VALIMIENTO DEL CONDE / DE OROPESA. / AÑO DE 1687. / POR DON LUIS DE SALAZAR Y CASTRO. Publicado en S.E., tomo II, páginas 129-144.

b) Obras de tipo episcopalista.

*13) Garcerán Albanel: CARTA / Que de órden del Señor Don Felipe IV. se remitió al llus- / trísimo Señor Don Garcerán Albanel, su Maestro, y Arzo-I bispo de Granada, para que informase sobre el Breve de / su Santidad en razón de Residencia de los Obispos / en sus Iglesias. Publicado en S.E., tomo XIV, páginas 205-217.

(Se incluye la respuesta del arzobispo, rotulada Parecer del llustrisimo Señor Arzobispo, págs. 205-217).

B) Obras regalistas del siglo XVIII.

a) Obras de tipo jurisdiccional.

1) Melchor de Macanaz: AUXILIOS / PARA BIEN GOBERNAR / UNA MONARQUIA CATOLICA, / O DOCUMENTOS, / Que dicta la experiencia, y aprueba la razon, para que / el Monarca merezca justamente el nombre / de Grande. / OBRA, / QUE ESCRIBIO, Y REMITIO DESDE PARIS / AL REY NUESTRO SEÑOR / DON FELIPE QUINTO / DON MELCHOR DE MACANAZ, etc. Publicado en S.E., tomo V, páginas 215-303.

2) Melchor de Macanaz: REPRESENTACION / QUE HICE Y REMITI DESDE LIEJA / AL SEÑOR REY / DON FELIPE QUINTO, / Expresando los notorios males que causan la despobla- / ción de España y otros daños sumamente atendibles / y dignos de reparo; con los generales adverti- / mientos para su universal remedio. Publicado en S.E., tomo VII, 158-204.

*3) Melchor de Macanaz: DISCURSO / SOBRE EL PODER QUE ALGUNOS DOCTORES / han querido atribuir al Papa en lo temporal. / ESCRITO / POR DON MELCHOR RAFAEL DE MACANAZ. / AÑNO DE 1717. Publicado en S.Ex, tomo VIII, páginas 136-160. 
4) Melchor de Macanaz: AVISOS POLITICOS, I MAXIMAS PRUDENTES, / Y REMEDIOS UNIVERSALES, QUE DICTA / la experiencia, / Y REM TE / AL SEÑOR REY DON FERANDO (sic) EL VI. / en el principio de su reynado, para que su práctica restablezca / la decadencia de la Monarquía Española, de los innu- / merables males que padece, / DON MELCHOR RAFAEL DE MACANAZ. Publicado en S.E., tomo VIII, páginas 217-237.

*5) Melchor de Macanaz: EXPLICACION JURIDICA / É HISTORICA / DE LA CONSULTA / QUE HIZO EL REAL CONSEJO DE CASTILLA / AL REY NUESTRO SEÑOR, / Sobre lo que S.M. se sirvió preguntarle, y se ex- / presa en esta obra; con los motivos que dieron cau- / sa para la real pregunta y la respuesta. $Y$ defen- / sa legal de una de las principales partes, que / componen el todo de la soberania / de su Magestad. / POR DON MELCHOR DE MACANAZ. I Trabajado todo de real y secreto mandato de S.M. Publicado en S.E., tomo IX, páginas 3-142.

6) Melchor de Macanaz: DISERTACION HISTORICA, / QUE SIRVE DE EXPLICACION / A ALGUNOS LUGARES OBSCUROS / QUE SE ENCUENTRAN EN LA HISTORIA, / Cartas, Alegaciones y Apologia que ha dado á luz el / Cardenal Alberoni. / POR D. MELCHOR RAFAEL DE MACANAZ. Publicado en S.E., tomo XIII, páginas 3-90.

7) Juan Ortí (atribuido): REPAROS CRITICOS, I fundados en hechos verdaderos, contra varios pasages que / refiere el Marques de San Felipe en sus Comentarios de la / Guerra de España, que escribio un Valenciano en obsequio / de la verdad, y lealtad de su Patria. Publicado en S.E., tomo XVIII, páginas 68-224.

(Obra antirregalista, pero que ofrece una visión sobre la actuación de Macanaz en Valencia, y como Fiscal).

*8) Santiago Agustín Riol: INFORME / QUE HIZO A SU MAGESTAD / EN 16 DE JUNIO DE 1726. I DE SU REAL ORDEN / DON SANTIAGO AGUSTIN RIOL, / SOBRE / la creacion, ereccion é institucion de los Consejos, y I Tribunales; las Instrucciones que se les impusieron / para obrar segun su instituto; el estado que hoy tie- / nen los papeles de sus Archivos, y la forma de su an- / tiguo, y actual manejo; las causas que hubo en cada / uno para perderse, ó minorarse; los que exîsten en / el Archivo de Simancas, con distincion de su clase y / naturaleza; la fundación de aquel Real Archivo, el de / Barcelona, y Roma; el actual estado del manejo de sus / papeles, 
y colocación; el paradero que han tenido los / causados en Juntas particulares, mandadas formar / para diversos negocios, de varios Ministros; los de / los Embaxadores, y Ministros públicos de fuera; Va- / lídos, primeros Ministros, y Confesores de los Reyes predecesores, etc. Publicado en S. E., tomo III, páginas 73-234.

*9) Santiago Agustín Riol: REPRESENTACION / SOBRE EL PATRONATO REAL, / QUE DIO MOTIVO / A LAS NOVEDADES DEL AÑO DE 1735. / DADO / POR DON SANTIAGO RIOL. Publicado en S.E., tomo VI, páginas 82-98.

10) Vicente Cangas Inclán: CARTA, / O REPRESENTACION / AL SEÑOR REY / DON FELIPE QUINTO, / SOBRE / EL ORIGEN Y SERIE DE LAS CORTES; / sus providencias y utilidad; origen de las imposiciones / y sus fines; motivos de las carestias y baraturas; re- / flexîones sobre la mejor administración de Justicia, / gracias, Policia, Economia, Guerra, Hacienda, / y otras cosas en beneficio del Rey, / y del reyno. / POR / DON VICENTE DE CANGAS INCLAN. Publicado en S.E., tomo III, páginas 237-269.

11) Anónimo: ABUSOS / QUE SE COMETEN / EN EL MANEJO Y DIRECCION / DE TODAS LAS RENTAS REALES. / UNIVERSALES REMEDIOS PARA QUE LOGRE EL ERARIO / LOS BENEFICIOS QUE HOY LE FALTAN, Y LA MONARQUIA / ESPAÑOLA TODA LA GLORIA Y EXPLENDOR / QUE MERECE. Publicado en S.E., tomo XI, páginas 36-80.

12) Marqués de la Ensenada: REPRESENTACION / HECHA AL SR. D. FERNANDO EL VI. / POR SU MINISTRO / EL MARQUES DE LA ENSENADA, I Proponiendo medios para el adelantamiento de la Monarquía, y buen gobierno de ella. Publicado en S.E., tomo XII, páginas 260-282.

13) Anónimo: REPRESENTACION / HECHA AL EXMO. SR. MARQUES DE LA ENSENADA, / SOBRE / la política exterior é interior de España: graves advertencias, / finas disposiciones, y utilísimas providencias, para que me- / diante la feliz aptitud que hay en ella, sea la Empera-/ triz del Universo. / POR / el mas afectísimo servidor de S.E. que desea sus aciertos, y / la gloria de la nacion, lo que se logrará con la práctica / que ofrece este escrito. Publicado en S.E., tomos XIV, páginas 218-284, y XV, páginas 3-49.

14) Lorenzo Sagarzazu: REGLAS $Y$ DOCUMENTOS / DADOS / AL SR. REY FERNANDO EL VI. / para la conservación y aumento de su grandeza y soberanía, con utilidad de su real erario, y beneficio / de sus vasallos. / POR / EI DOCTOR DON LORENZO SAGARZAZU. Publicado en S.E., tomo XIII, páginas 217-232. 
*15) Ximeno: PREGUNTA / de Don Ximeno, Regente de Valencia. Agustín Sales: RESPUESTA / que dió el Doctor Don Agustin Sales, Presbitero, / Coronista de Valencia. Publicado en S.E., tomo XVI, páginas 224-230.

16) Miguel Antonio de la Gándara y Pérez de Villaviad: INFORME RESERVADO / QUE HIZO A S.M. / EN VIRTUD DE REAL ORDEN, / D. MIGUEL ANTONIO DE LA GANDARA, / SOBRE / UN MANIFIESTO DEL OBISPO DE AVILA, RELATIVO I Á VARIOS PUNTOS DEL CONCORDATO. Publicado en S.E., tomo XII, páginas 3-56.

b) Obras de tipo episcopalista.

*17) Francisco de Solís: DICTAMEN / QUE DE ORDEN DEL REY, / COMUNICADA / POR EL MARQUES DE MEJORADA, / SECRETARIO DEL DESPACHO UNIVERSAL, I con los papeles concernientes que habia en su Secretaría, dio / el llustrísimo señor D. Francisco de Solís, Obispo de Cordoba, / y Virrey de Aragon, en el año de 1709. / SOBRE / los abusos de la Corte Romana, por lo tocante á las Regalías de / S.M. Católica, y jurisdiccion que reside en los Obispos. Publicado en S.E., tomo IX, páginas 206286.

*18) Fr. Joseph Haro de San Clemente: MEMORIAL / AL REY NUESSEÑOR / DON FELIPE QUINTO / (QUE DIOS GUARDE) /Satisfaciendo á otro, que en nombre de todas las Re- / ligiones se presentó a S.M. para impedir la execu- / ción de la Bula Apostolici Ministerii en estos / sus reynos y señorios: / SU AUTOR / FRAY JOSEPH HARO DE SAN CLEMENTE, / del Orden de Ntra. Sra. del Carmen de la antigua Re- / gular Observancia, Dr. Te' ologo, Mtro Decano, y Di- / finidor perpetuo de la Provincia de Andalucía, Protono- / tario y Predicador Apostólico, natural de la Ciudad / y Puerto de S. Lucar de Barrameda. Publicado en S.E., tomo XV, páginas 50-112.

*19) Gregorio Mayáns y Siscar: Cartas eruditas y críticas de Don Gregorio Mayáns / y Siscar, á varios asuntos; con la nota del Editor. Publicado en S.E., tomo XVIl, páginas 3-231. 
*20) Gregorio Mayans y Siscar: CONCORDATO / Ajustado entre el Señor D. Fernando VI Rey de España, / y la Santidad de Benedicto XIV á 20 de Febrero de 1753, / con las observaciones que sobre el mismo concordato hizo / D. Gregorio Mayans y Siscar, Bibliotecario mayor (sic) de S.M. I en que recopila las grandes utilidades, que de él resultan á la Corona. Publicado en S.E., tomo XXV, páginas 3-288 (íntegro), y tomo XXVI, páginas 3-117. 